\title{
HDL: More Than Just Cholesterol
}

\author{
Anna Meiliana ${ }^{1,2 *}$ and Andi Wijaya ${ }^{1,2 *}$ \\ ${ }^{1}$ Post Graduate Program in Clinical Biochemistry, Hasanuddin University, Makassar \\ ${ }^{2}$ Prodia Clinical Laboratory, Jakarta \\ *Address correspondence to this author at: Prodia Clinical Laboratory, Jl. Cisangkuy No.2, Bandung \\ E-mail: anna_m@prodia.co.id, andi_w@prodia.co.id
}

\section{Abstract}

$\mathrm{B}$

ACKGROUND: Plasma concentration of high density lipoprotein cholesterol (HDL-C) are strongly, consistenly, and independently inversely associated with risk of atheroschlerotic cardiovascular disease (CVD). However, the last decade has se, several observations that do not follow this simple script.

CONTENT: A proteomic analysis of HDL has given us an intriguing glimpse into novel components of HDL. HDL isolated from normal humans contains several classes of proteins, including not only apolipoproteins, but also complement regulatory proteins, endopeptidase inhibitors, hemopexin, and acute phase response proteins. These observations raise the possibility of unsuspected roles for HDL. HDL delivery of complement proteins would implicate HDL in innate immunity. Serine proteinase inhibitors would enable HDL to modulate proteolysis of the vessel wall. HDL from patients with coronary artery disease was enriched in apoE, apoC-IV, apoA-IV, Paraoxonase (PON), and complement factor C3. Highlighted additional mechanisms through which HDL protects the vessel wall are: HDL improves vascular function, decreases vascular inflammation, detoxifies radicals, and limits thrombosis.

SUMMARY: Both inter- and intraorgan desynchrony may be involved in the pathogenesis of cardiometabolic disease attributable to effects in brain and multiple metabolic tissues including heart, liver, fat, muscle, pancreas, and gut. Efforts to dissect the molecular mediators that coordinate circadian, metabolic, and cardiovascular systems may ultimately lead to both improved therapeutics and preventive interventions.

KEYWORDS: HDL, Apo-Al, RCT, Inflammation, HDL Dysfunction, HDL Proteome, HDL \& Apo-A1 Mimetics.

\section{Introduction}

Despite strong evidence for an inverse association between HDL-C levels and cardiovascular risk (1), successful therapeutic strategies to target HDL have remained elusive. A recent Phase III clinical trial failed to show clinical benefit with the cholesteryl ester transfer protein inhibitor torcetrapib despite markedly increased HDL-C levels $(2,3)$. This outcome reinforced a growing consensus that measurement of HDL-C alone may be an incomplete surrogate for the in vivo functionality of HDL and the clinical efficacy of targeting HDL. The careful mechanistic assessment of HDL function has thus emerged as a potential way forward (4).

There is great interest in understanding the ability of HDL to mediate Reverse Cholesterol Transport (RCT) from macrophages because this ability underlies the antiatherogenic functions of the lipoprotein. Recent studies show that macrophage RCT mediated by HDL has important implications for the development of atherosclerosis, but the HDL contribution does not correlate 
well with the HDL-C levels, the increase in HDL-C due to elimination of Scavenger Receptor Class B type I (SR-BI) is associated with decreased RCT and increased atherosclerosis. These results indicate that the rate of macrophage RCT and the quality rather than the quantity of HDL are important in determining the antiatherogenic effects of HDL (5).

The ability of HDLtoremove cholesterol and oxysterols from cells such as macrophages in the arterial wall is linked to the anti-inflammatory and immunosuppressive functions of this lipoprotein $(6,7)$. These capabilities coupled with the antioxidant, antithrombotic and vasodilatory capabilities of HDL (8) give rise to the overall cardioprotective behavior of HDL. It is becoming increasingly apparent that these antiatherogenic effects of HDL are not only dependent on its concentration in circulating blood but also on its biological quality (9-11).

The functionality of HDL is impaired in humans with chronic inflammatory diseases, including atherosclerosis (12), and these deleterious effects can involve oxidative modification of Apolipoprotein A-I (apoA-I) (13). The HDL dysfunction involves reductions in both anti-inflammatory and cholesterol transport properties. Proteomic studies that have been conducted recently in various laboratories (14) exemplify the growing interest originating from clinical observations on the atheroprotective properties of HDL. What is emerging is that the HDL proteome contains, in addition to the previously recognized quantitatively "minor" apolipoproteins, enzymes, and transport proteins relevant to lipid metabolism and many others that are not in the lipid area but are involved in the processes of acutephase response, proteinase inhibition, and complement regulation. The presence of small peptides and fragments of yet unknown function has also been reported (15). This unsuspected array of HDL-associated proteins with a marked diversity in biological function has opened new avenues of investigations that may provide a better understanding of the role played by HDL in atherogenesis and inflammatory processes in general and help identify novel biomarkers of cardiovascular disease (16).

\section{HDL Heterogeneity}

HDL is a complex macromolecule comprised of lipids (phospholipids and unesterified free cholesterol on the surface and cholesteryl ester and triglycerides in the core) and proteins (apolipoproteins and a variety of other proteins in smaller amounts). Multiple subfractions of
HDL based on density, size, charge, and composition can be identified in plasma. A topic of considerable interest is whether specific subfractions of HDL confer greater ability to predict cardiovascular risk than HDL-C itself or may be of greater utility in assessing the benefits of a therapeutic intervention targeted to HDL. Patients with coronary disease generally have smaller, denser HDL particles, leading to the concept that larger HDL particles may be associated with greater protection from CHD. However, the data regarding the predictive ability of HDL subclasses for CHD risk are not conclusive. Recent study indicate that there is a direct relationship between HDL size, apoAI content, and Lecithin Cholesterol Acyl Transferase (LCAT) activation, that different subclasses of particles have distinct morphology and stability, and that spontaneous remodeling of HDL particles represents a potential mechanism for the generation of lipid-free/lipidpoor apoA-I in vivo (17).

HDL can be fractionated into discrete subclasses by different techniques according to their physicochemical properties. Human HDL can be separated by ultracentrifugation into two main subfractions on the basis of density, $\mathrm{HDL}_{2}(1.063-1.125 \mathrm{~g} / \mathrm{ml})$ and $\mathrm{HDL}_{3}(1.125-1.21 \mathrm{~g} / \mathrm{ml})$, which is relatively protein-rich. $\mathrm{HDL}_{2}$ and $\mathrm{HDL}_{3}$ can be further divided on gradient gel electrophoresis into $\mathrm{HDL}_{2 \beta}$ $(10.6 \mathrm{~nm}), \mathrm{HDL}_{2 \alpha}(9.2 \mathrm{~nm}), \mathrm{HDL}_{3 \alpha}(8.4 \mathrm{~nm}), \mathrm{HDL}_{3 \beta}(8.0$ $\mathrm{nm})$ and $\mathrm{HDL}_{3 \mathrm{c}}(7.6 \mathrm{~nm})$ in decreasing order of particle diameter (18). In addition, HDL can be separated into two main subpopulations on the basis of electrophoretic mobility: the major subfraction has a relatively high negative surface charge density and is called $\alpha$-HDL, whereas the other fraction is called pre $\beta$-HDL $(19,20)$. Most of the HDL particles in plasma are $\alpha$-HDL (21) and pre $\beta$-HDL represents only approximately $5 \%$ of total apoA-I(22).

Pre $\beta$-HDL has been resolved into pre $\beta_{1}$, pre $\beta_{2}$ and pre $\beta_{3}$ HDL particles according to increasing size by twodimensional gel electrophoresis (20). ApoA-I is the only protein constituent of these nascent HDL particles but, interestingly, if apoM is also expressed by the cells, the particle size increases. ApoM may function intracellularly to transfer lipid onto the HDL particles during or after their formation by ATP-Binding Cassette A1 (ABCA1) (23). Depending upon cell type, $\alpha$-HDL and/or pre $\beta$-HDL particles can be formed by the apoA-I/ABCA1 reaction (24).

Apolipoprotein $\mathrm{F}(\mathrm{ApoF})$ is a protein component of several lipoprotein classes including HDL. It is also known as lipid transfer inhibitor protein (LTIP) based on its ability to inhibit lipid transfer between lipoproteins $e x$ vivo. ApoF overexpression reduces HDL cholesterol levels in mice by increasing clearance of HDL-CE. ApoF may be 


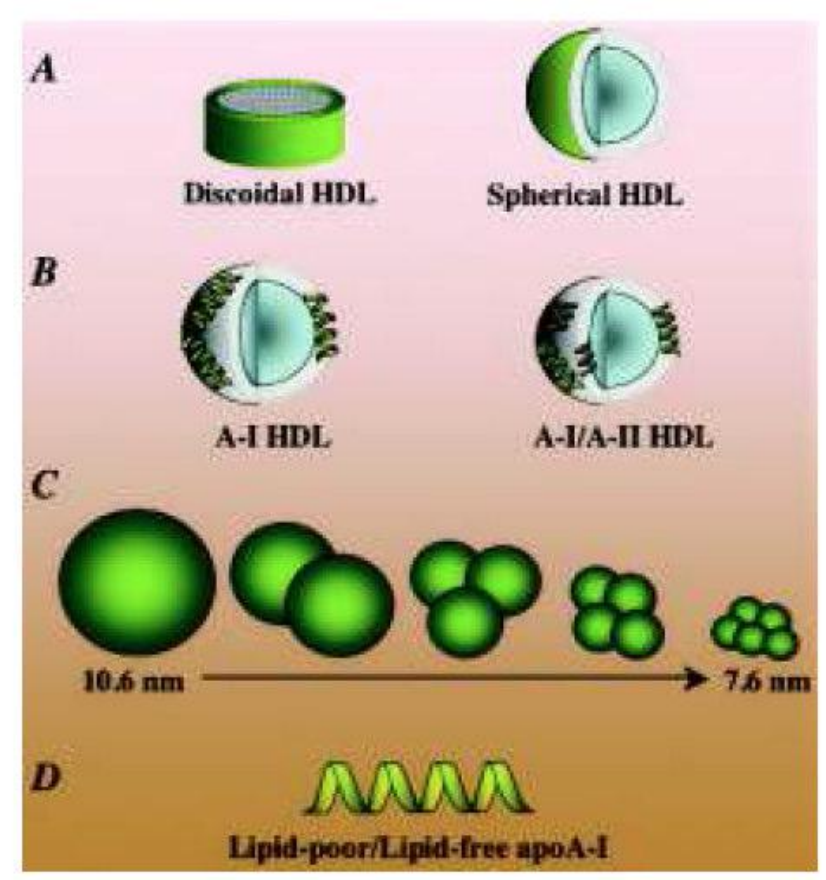

Figure 1. Heterogeneity of HDL subpopulation (Reproduced with permission, from F. Tabet and K.-A. Rye. Clinical Science 2009; 116: 87-98. (c) the Biochemical Society.)

an important determinant of HDL metabolism and reverse cholesterol transport (25).

Choline-containing phospholipids (phosphatidylcholine, lysolecithin, sphingomyelin) represent 90-95\% of the phospholipids in HDL (26). The calculated lipid composition is 137 phospholipids, 50 free (unesterified) cholesterol, 90 cholesterol ester and 19 triacylglycerol molecules in an $\mathrm{HDL}_{2}$ particle, and 51 phospholipids, 13 free cholesterol, 32 cholesterol ester and nine triacylglycerol molecules in an $\mathrm{HDL}_{3}$ particle (27). Pre $\beta$-HDL contains mainly apoA-I and phospholipids with small amounts of cholesterol $(22,28)$.

Indeed, there is considerable variation among individuals with similar HDL-C concentrations with regard to the ability of their serum to promote cholesterol efflux ex vivo $(29,30)$, and some evidence that even after normalization, some HDL particles are more effective at promoting efflux than others (31). Thus the ability to assay human serum or isolated HDL for its cholesterol efflux capacity could be an important method of determining HDL function in assessing differences among individuals or in response to novel therapies.

Robust laboratory assays of HDL subfractions and functions and validation of the usefulness of these assays for predicting cardiovascular risk and assessing response to therapeutic interventions are critically important and of great interest to cardiovascular clinicians and investigators and clinical chemists (11).

\section{Dysfunctional HDL}

RCT is the process by which cholesterol in peripheral cells (eg, lipid-laden foam cells) is effluxed onto circulating HDL and transported back to the liver for secretion into bile and feces $(32,33)$. Promotion of RCT is considered a major antiatherogenic function of HDL (34).

It is well established that HDL-C concentration in the blood is independently and inversely associated with an increased risk of CVD $(35,36)$. However, it is apparent that many patients with 'normal' or even 'elevated' plasma HDL experience clinical events (37). Furthermore, the recent clinical trial ILLUMINATE, which targets to increase plasma HDL levels with a new selective Cholesterol Ester Transfer Protein (CETP) inhibitor, Torcetrapib, was prematurely terminated because of an increase in all-cause mortality despite an increase in HDL-C levels. These disappointing results suggest that HDL may not always be atheroprotective $(38,39)$, and in some conditions, it paradoxically enhances the process of atherosclerosis (40).

Fogelman and colleagues developed an assay to measure the antiinflammatory activity of HDL by determining the extent to which HDL inhibits monocyte chemotaxis induced by LDL using an in vitro reconstituted artery wall model by the coculture of smooth muscle cells 
and endothelial cells (41). Other assays for HDL function include cell free antioxidant activity (42), inhibition of endothelial cell adhesion molecule expression (43), and the ability of HDL to act as an acceptor of cellular cholesterol. Navab, Fogeleman, and colleagues using this artery wall model system have demonstrated several conditions in which HDL can lose its antiinflammatory properties, including during the acute phase response when serum amyloid A partially replaces apoAI in HDL, during influenza A infection, and in apolipoprotein AII transgenic mice (44-46).

HDL from Coronary Artery Disease (CAD) subjects is dysfunctional. In fact, HDL from many CAD patients was actually proinflammatory, thus increasing monocyte chemotaxis in response to LDL, unlike the HDL from healthy controls that reduced monocyte chemotaxis. There are many possible alterations between this dysfunctional HDL and normal functional HDL (42).

Inflammation induces major changes in HDL levels and composition. Mediators of inflammation such as tumor necrosis factor (TNF)- $\alpha$ and interleukin (IL)-6 induce expression of serum amyloid A (47) and group IIA secretory phospholipase A2 (sPLA2-IIA) (48), which dramatically alter HDL apolipoprotein content and levels, respectively. Acute phase Serum Amyloid A (SAA) in the plasma is associated with HDL, where it can comprise the major apolipoprotein (49). The increase in sPLA2- IIA activity results in hydrolysis of HDL surface phospholipids and a decrease in HDL particle size (50). The plasma CETP is an integral component of reverse cholesterol transport and regulates HDL cholesterol concentrations. By promoting the transfer of cholesteryl esters (CE) from HDL to apoBcontaining lipoprotein particles, HDL-derived CE is taken up via the LDL receptor and cleared by the liver (51). An additional result of CETP action is the generation of lipidpoor apoA-I (52), a key acceptor in ATP-binding cassette transporter AI (ABCA1)- mediated lipid efflux (53). The presence of SAA on HDL holds the potential to impact both the CE transfer and the apoA-I liberating ability of CETP. sPLA2-IIA could also impact the latter action of CETP as apoA-I was shown to dissociate more readily from CETP-remodeled reconstituted HDL after hydrolysis by bee venom phospholipase A2 (54).

Teleologically, the dramatic changes in HDL composition and metabolism during inflammation must serve a short-term purpose to allow the organism to survive a noxious assault. Acute tissue injury results in cell death with large quantities of cell membranes rich in phospholipids and cholesterol generated. Macrophages are mobilized to such sites, ingest these fragments, and acquire considerable lipid load (55).
Another factor that might make HDL dysfunctional is a change in the HDL-associated lipids. HDL may acquire oxidized lipids from cells and by exchange with other particles, or HDL lipids may be oxidized in situ. Lipid peroxides may interfere with HDL antioxidant, antiinflammatory, and cholesterol acceptor activities. Fully functional HDL may promote lipid hydroperoxide metabolism and its uptake and clearance by the liver, which would be protective (56). In contrast, dysfunctional HDL might promote the transfer of lipid hydroperoxides to apoB-containing lipoproteins and promote VLDL and LDL oxidation (57).

Myeloperoxidase (MPO) is an enzyme found in neutrophils, monocytes, and some macrophages that uses hydrogen peroxide to generate chlorinating and nitrating oxidants, which play an important role in killing microorganisms. However, these same reactive species can also modify host proteins and lipids. MPO is enriched in human atheroma (39), and its presence may promote lesion progression, by increasing LDL oxidation, and block plaque regression, by modifications of apoAI/HDL that impair RCT. Bergt et al. demonstrated that incubation of $\mathrm{HDL}$ with MPO, in a chlorinating reaction $\left(\mathrm{MPO} / \mathrm{H}_{2} \mathrm{O}_{2}\right.$ / $\mathrm{Cl}^{-}$) that produces $\mathrm{HOCl}$ (chlorine bleach), or with reagent $\mathrm{HOCl}$ (at a very high 100:1 ratio of $\mathrm{HOCl}$ :apoAI) leads to a loss of unsaturated fatty acids in phospholipids and cholesterol esters, and the loss of cholesterol acceptor activity (40).

In addition to decreased lipid acceptor activity, Panzenboeck et al. also showed that $\mathrm{MPO}-$ or $\mathrm{HOCl}-$ modified HDL was more susceptible to uptake and degradation by macrophages, thus turning HDL from a lipid-accepting lipoprotein to a lipid-loading lipoprotein (61).

MPO modification of apoAI is physiologically relevant by demonstrating that: (1) apoAI in plasma and more so in arterial lesions is a selective target of MPO modification that leads to the nitration and chlorination of specific apoAI tyrosine residues; (2) plasma apoAI nitroand chloro-tyrosine levels are higher in coronary artery disease patients than in control subjects; and (3) apoAI tyrosine chlorination, whether in endogenous plasma or after in vitro MPO-mediated modification, is associated with the specific loss of ABCA1-mediated cholesterol acceptor activity, such that apoAI cholesterol acceptor activity was inversely correlated with apoAI nitro-and chloro-tyrosine levels (62-67).

Thus, the levels of plasma apoAI nitro-and chloro-tyrosine may serve as physiological useful and specific markers of MPO activity in vivo, even though tyrosine modification does not appear to be responsible 


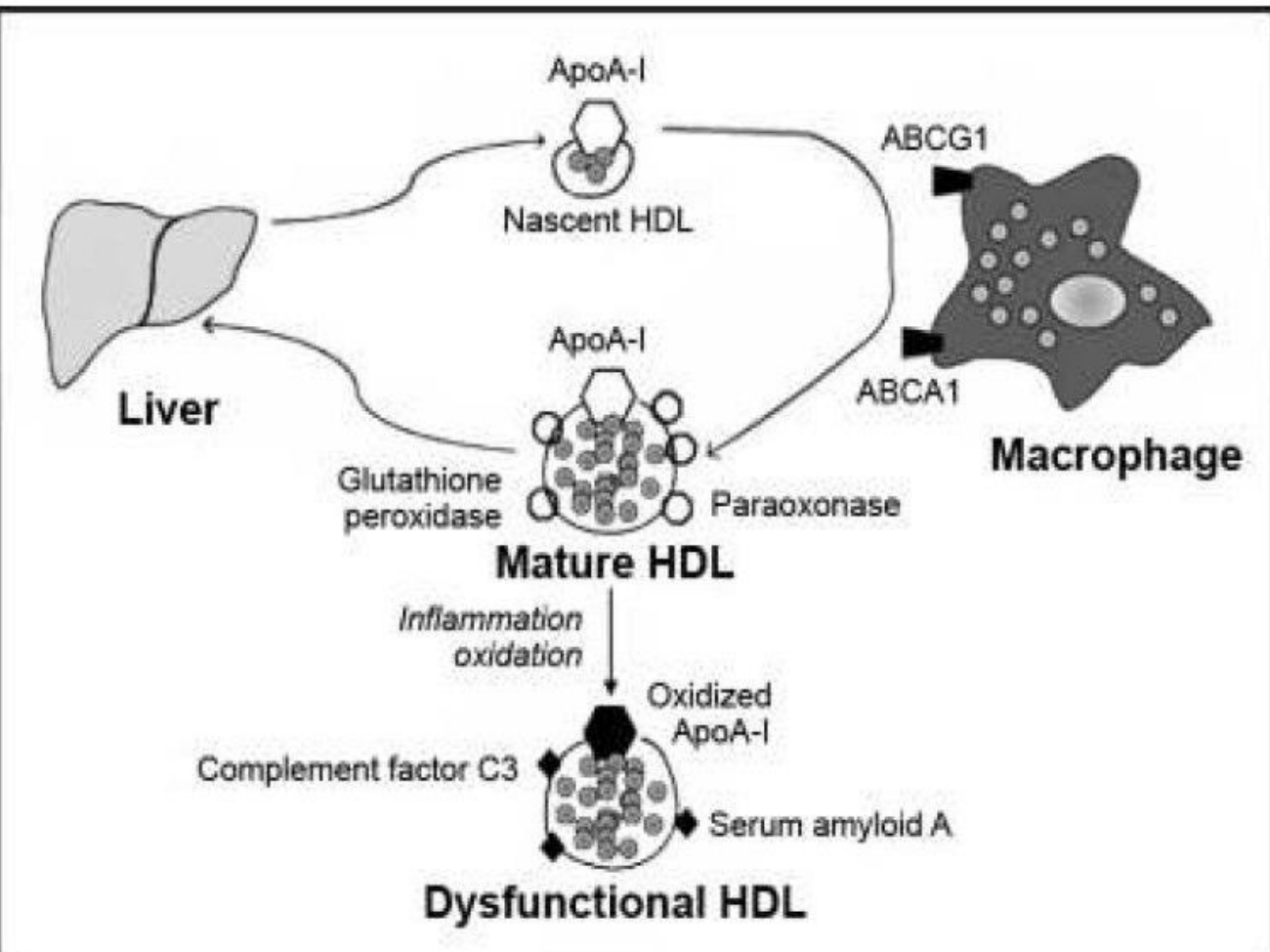

Figure 2. Mature and dysfunctional high - density lipoprotein (Reproduced with permission from Lowenstein CJ, Cameron SJ. Curr Opin Endocrinol Diabetes Obes 2010; 17: 166-70. (C) Lippincott William \& Wilkins).

for turning the "good" HDL-cholesterol "bad." ApoAI activity appears to require both hydrophobic and aromatic residues in the Trp positions. When the $4 \mathrm{WF}$ and wildtype apoAI isoforms were treated with increasing oxidant stress from MPO or $\mathrm{HOCl}$, the $4 \mathrm{WF}$ isoform is markedly resistant to loss of cholesterol acceptor activity (68). Thus, the $4 \mathrm{WF}$ apoAI isoform is MPO resistant and may be a better therapeutic reagent to promote the regression of atherosclerotic plaques, an environment where MPO and MPO-derived oxidants are abundant. If this strategy is successful, then "good" cholesterol can be made "better" (13).

Zheng et al., using mass spectrometry, demonstrated that the level of apoAI chlorotyrosine was a better predictor of cardiovascular disease than the levels of total plasma chloro- or nitro-tyrosine (62). This type of assay is more specific for dysfunctional HDL but is too laborious for routine clinical use. The identification of specific modified residues in apoAI, such as chlorotyrosine and hydroxytryptophan, make it possible to develop novel and scalable immunoassays specific for oxidized/dysfunctional HDL. Through the development of these new assays it will be possible to perform observational and interventional studies to determine the association of dysfunctional HDL with CAD, cerebrovascular events, and mortality (13).
Inflammation is proposed to impair HDL function and RCT. This may be of pathophysiological significance because attenuation of RCT might contribute to atherosclerosis in chronic inflammatory states, including metabolic syndrome and T2DM (69).

\section{Cardiovascular Protective Effects of HDL Beyond RCT}

The cardioprotective effects of HDLs have been attributed to several mechanisms, including their involvement in the reverse cholesterol transport pathway. HDLs also have antioxidant, anti-inflammatory amd antithrombotic properties and promote endothelial repair, all of which are likely to contribute to their ability to prevent CHD (8).

The central anti-atherogenic activity of HDL is likely to be its ability to remove cholesterol and oxysterols from macrophage foam cells, smooth muscle cells and endothelial cells in the arterial wall. To some extent, the pleotropic atheroprotective properties of HDL may be related to its ability to promote sterol and oxysterol efflux from arterial wall cells, as well as to detoxify oxidized phospholipids (6). 
Atherosclerosis, once regarded simply as excessive accumulation of lipids in the artery wall, is now considered to be a chronic inflammatory disorder that is characterized by the presence of macrophages and other inflammatory cells in the arterial intima (70).There is mounting evidence that HDLs inhibit the inflammation that is associated with atherosclerotic plaque development, including the initial step, where circulating leucocytes become tethered to the endothelial surface and migrate into the artery wall (71).

The death of macrophages in atherosclerotic lesions by apoptosis or postapoptotic necrosis is thought to contribute to inflammation, necrotic core formation and destabilization of plaques (72-75). Recent study shown that HDL reduces macrophage apoptosis induced by loading with free cholesterol or oxidized LDL (76). Interestingly, the ability of HDL to protect against apoptosis, especially that induced by oxidized LDL, is abolished in ATP Binding Cassette G1 (ABCG1) - / - macrophages. This reflects the specific ability of HDL and ABCG1 to promote efflux of 7-ketocholesterol and related oxysterols modified at the seventh position from macrophages loaded with oxidized LDL. In contrast, $\mathrm{ABCA} 1$ and apo $\mathrm{A}-1$ do not promote efflux of 7-ketocholesterol from cells. 7-Ketocholesterol is the major oxysterol found in oxidized LDL and atherosclerotic plaques. Consistent with an in vivo role of $\mathrm{ABCG} 1$ in promoting efflux of oxysterols, ABCG1 - / - mice show accumulation of 7-ketocholesterol in macrophages, as well as reduced levels of 7-ketocholesterol in plasma, when fed a high-cholesterol diet. These observations suggest a specific role of ABCG1 in promoting efflux of toxic oxysterols from plaque macrophages to HDL. As ABCG1 also appears to be highly expressed in arterial endothelium (77), this activity could also potentially protect against oxidized LDL-induced endothelial dysfunction and reduced endothelial nitric oxide synthase (eNOS) activity (78).

$\mathrm{ABCA} 1$ and $\mathrm{ABCG} 1$ are both induced in phagocytes following ingestion of apoptotic cells (79), and are involved in promoting cholesterol efflux after ingestion of the cholesterol-rich apoptotic cell, thus protecting the phagocyte from free cholesterol-induced cell death (80). The induction of ABCA1 involves both Liver X Receptors (LXRs) and activation of mitogen-activated protein kinase (MAPK) signalling pathways in phagocytes, specifically NFx $\beta$ and $\mathrm{p} 38$ MAPK signalling, whilst the induction of ABCG1 is mediated via LXRs (79).

Thus, in atherosclerotic plaques, the activities of ABCA1 and ABCG1 probably help to get rid of cholesterol, oxysterols and oxidized phospholipids that are taken up during ingestion of modified LDL or apoptotic cells. The efficient and healthy clearance of apoptotic cells is likely to be a key event limiting lesion progression, and the failure of this process may lead to directly to postapoptotic necrosis and inflammatory cell death, promoting plaque destabilization (74).

HDL has potent antiinflammatory properties, including the ability to directly bind and sequester lipopolysaccharide $(81,82)$, suppressing activation of Tolllike receptor 4 (TLR4) signaling (83). Recent studies have indicated additional direct cellular effects of HDL leading to suppression of inflammatory responses. By promoting cholesterol efflux, HDL has been proposed to inhibit cellular inflammatory signaling leading to inhibition of Monocyte Chemoattractant Protein-1 (MCP-1) and CD11b expression and monocyte transmigration (84).

These mechanisms (ie, increased sterol synthesis and decreased sterol efflux) likely help to conserve cellular cholesterol required for increased membrane synthesis during cell proliferation. Additional mechanisms may also be involved, such as changes in membrane lipid composition or organization that lead to enhanced growth factor receptor mediated signaling events. These studies strongly suggest that HDL-mediated cholesterol efflux via LXR-regulated $\mathrm{ABC}$ transporters plays a key role in downmodulating lymphocyte proliferation and activation. The sterol efflux activities of ABCA1 and ABCG1 modulate macrophage expression of inflammatory cytokines and chemokines as well as lymphocyte proliferative responses. In macrophages, transporter deficiency causes increased signaling via various Toll-like receptors including TLR4. Studies have shown that the traditional roles of HDL and $\mathrm{ABC}$ transporters in cholesterol efflux and reverse cholesterol transport are mechanistically linked to antiinflammatory and immunosuppressive functions of HDL. The underlying mechanisms may involve modulation of sterol levels and lipid organization in cell membranes (7).

Several lines of evidence suggest that HDLs have antioxidant properties, which may protect against oxidative damage in atherosclerosis. This beneficial effect has been attributed to enzymes, such as PON1 and plateletactivating factor acetylhydrolase (PAF-AH); also known as lipoprotein-associated phospholipase A2 (Lp-PLA2), present on the HDL surface $(85,86)$.

Oxidative stress, an emerging risk factor for premature atherosclerosis and cardiovascular disease, mediates the formation of proinflammatory, proatherogenic oxidized low-density lipoprotein (oxLDL) in the arterial intima. oxLDL contains multiple products of free radical-induced lipid peroxidation, including lipid hydroperoxides ( $\mathrm{LOOH})$ as primary products, secondary $\mathrm{LOOH}$-derived shortchain oxidized phospholipids (oxPL) and oxidized sterols (87). Significantly, products of lipid peroxidation present 
in oxLDL can induce a proinflammatory phenotype in arterial wall cells, which contributes to both endothelial dysfunction and apoptotic cell death, key elements in the initiation and progression of atherosclerotic lesions (88).

Apolipoprotein A-I (apoA-I), the major HDL apolipoprotein, may play a central role in HDL-mediated antioxidative activity, as Met residues 112 and 148 can reduce $\mathrm{LOOH}$ into redox-inactive lipid hydroxides $(\mathrm{LOH})$, thereby terminating chain reactions of lipid peroxidation $(89,90)$.

In addition to apoA-I, apolipoprotein components of HDL, which display antioxidative activity, include apoE, apoJ, apoA-II and apoA-IV. ApoE possesses distinct antioxidative properties (91) and can promote regression of atherosclerosis independently of reduction in plasma cholesterol levels (92-94). The beneficial actions of apoJ may be related to its ability to maintain integrity of membrane and lipoprotein lipids via its hydrophobicbinding domains (95).

The capacity of apoA-II to protect LDL from oxidation is however questionable, given the fact that overexpression of human apoA-II in dyslipidaemic mice accelerates atherosclerosis by altering the HDL proteome, by increasing aortic accumulation of oxLDL and by reducing antioxidative activity of HDL $(96,97)$. Such pro-atherogenic actions of apoA-II may be related to the displacement of antiatherogenic apoA-I and PON1 by apoA-II from HDL particles 97).
Enzymatic components potentially contributing to antioxidative properties of HDL include PON1, PAF-AH or 'lipoprotein-associated phospholipase A2' and LCAT, all of which were proposed to hydrolyse proinflammatory short-chain oxPL $(98,99)$. The distinction between the hydrolytic actions of HDL-associated PAF-AH and of PON1 on LOOH is however difficult as the two activities are typically determined using substrates, such as PAF (for PAF-AH) and paraoxon (for PON1), whose hydrolysis does not parallel the hydrolysis of $\mathrm{LOOH}(100)$.

The potent antioxidative activity of $\mathrm{HDL}_{3}$ critically involves transfer of phospholipid hydroperoxides (PLOOH) from oxLDL to $\mathrm{HDL}_{3}$ in a process dependent on HDL surface lipid rigidity, with concomitant reduction of LDLderived PLOOH to the corresponding redox-inactive PLOH by Met residues of apoA-I. Indeed, the transfer of LOOH from LDL to HDL can occur directly between lipoprotein phospholipid monolayers, either spontaneously or mediated by lipid transfer proteins $(101,102)$. Concentrations of redoxactive Met residues in apoA-I and of PLOOH suggest a $1: 1$ reaction stoichiometry $(89,90,103)$. Apo A-I therefore constitutes the central element in $\mathrm{HDL}_{3}$-mediated protection of LDL from free radical - induced oxidation.

HDL particles constitute a major carrier of $\mathrm{LOOH}$ in human plasma and have therefore been proposed to function as a 'sink' for oxidized lipids (56) which can accumulate when LOOH-inactivating capacity of HDL is overwhelmed. Consistent with this hypothesis, HDL
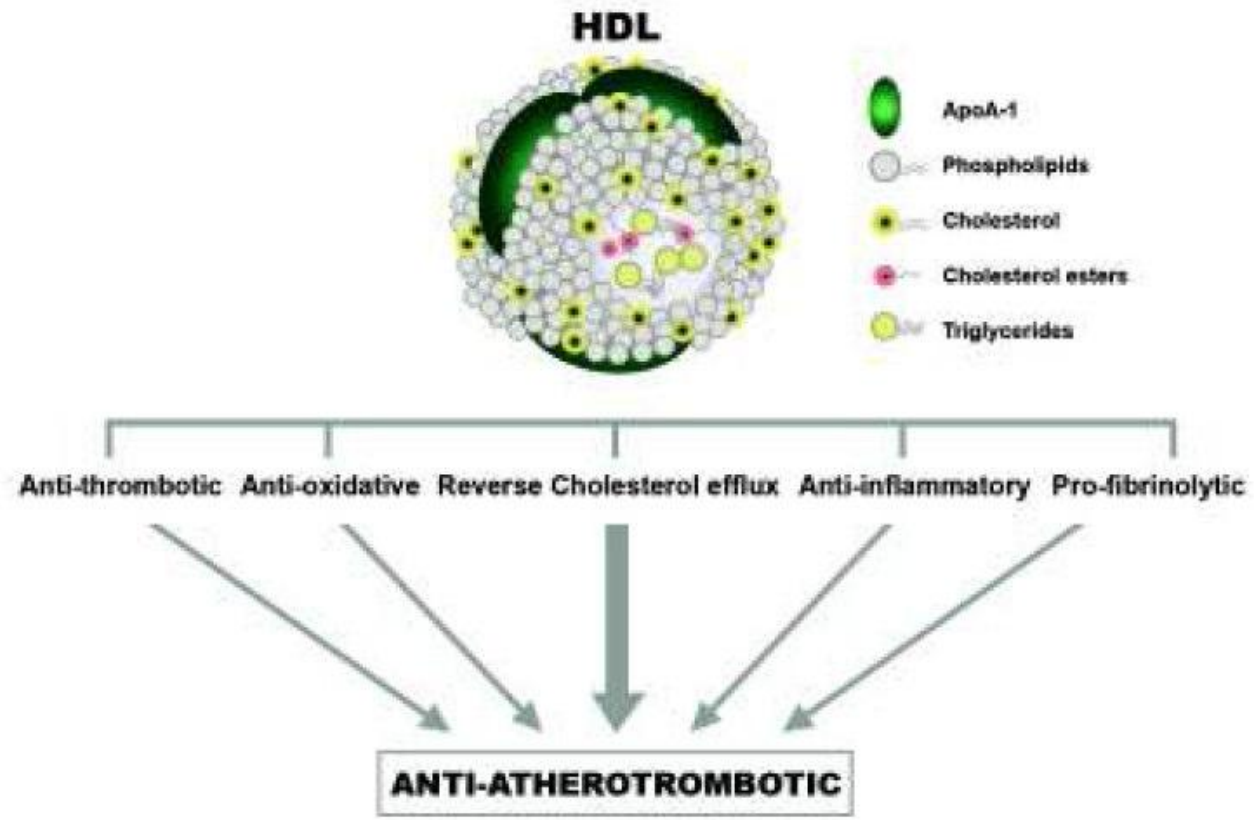

Figure 3. Antiatherothrombotic effects of HDL (Reproduced with permission from Skajaa T, Cormode DP, Falk E, Mulder WJM, Fisher EA, Fayad ZA. Arterioscler Thromb Vasc Biol 2010; 30: 169-76. ( American Heart Association). 
has been recently shown to represent the major carrier of plasma F2-isoprostanes, stable end-products of lipid peroxidation (104). From the physiological point of view, such 'sink'-like function of HDL may ensure efficient elimination of oxidized lipids from the circulation through the liver (101).

HDL particles are highly heterogeneous in their structure, metabolism and biological functions (98). Among the major HDL subpopulations, small, dense, protein-rich $\mathrm{HDL}_{3}$ are distinguished by their proteome and lipidome $(105,106)$. Furthermore, $\mathrm{HDL}_{3}$ exhibit potent capacity to protect LDL from free radical-induced oxidative damage (107) and to inhibit oxLDL-induced apoptosis of endothelial cells (108). Atheroprotective properties of small, dense $\mathrm{HDL}_{3}$ are consistent with results of clinical and animal studies $(109,110)$.

The most interesting of these identified small dense $\mathrm{HDL}_{3} \mathrm{c}$ as a particle subpopulation in which seven proteins occurred predominantly: apoA-I, apoJ, apoL-1, apoF, PON1/3, PLTP and PAF-AH $(105,106)$. The $\mathrm{HDL}_{3} \mathrm{c}$ proteome also contained apoA-II, apoD, apoM, SAA 1, 2 and 4 , apoC-I, apoC-II and apoE. The unique proteome of $\mathrm{HDL}_{3} \mathrm{c}$ has critical functional implications as this particle species exhibited the greatest potency among HDL subpopulations to protect LDL against oxidative stress in vitro. Such antioxidative activity was positively correlated with the presence of apoJ, apoM, SAA4, apoD, apoL-1 and $\mathrm{PON} 1 / 3$ in $\mathrm{HDL}_{3} \mathrm{c}$ (106).

Replacement of apoA-I by acute phase proteins, primarily SAA, in small, dense HDL particles under conditions of chronic inflammation (111) may represent another mechanism contributing to the impairment of HDL antioxidative activity. Thus, circulating HDL particles, and particularly small, dense, protein-rich $\mathrm{HDL}_{3}$, may provide potent protection of LDL in vivo from oxidative damage by free radicals in the arterial intima, resulting in the inhibition of the generation of proinflammatory oxidized lipids, primarily lipid hydroperoxides ( $\mathrm{LOOH})$ but also short-chain oxidized phospholipids (oxPL) (112).

Our understanding of the role of apoA-I/HDL in cardiovascular health and disease has entered a new era recently with the discovery that HDL has direct actions on the vascular endothelium and on mechanisms mediating thrombosis. In particular, the capacity of HDL to modify endothelial NO synthase (eNOS) expression and activity and the production of the atheroprotective signaling molecule nitric oxide (NO). Multiple lines of investigation indicate that $\mathrm{NO}$ is atheroprotective and that NO deficiency is critically involved in the pathogenesis of hypercholesterolemia-induced vascular disease. Because eNOS activity is acutely regulated by multiple extracellular stimuli and the NO produced is a labile, cytotoxic messenger molecule with primarily paracrine function $(114,115)$, the intracellular site of NO synthesis has a major influence on the biological impact of the enzyme. In cultured endothelial cells, eNOS is primarily associated with caveolae $(115,116)$. Caveolae are specialized, lipid-ordered plasma membrane microdomains enriched in cholesterol, glycosphingolipids, sphingomyelin, and lipid-anchored membrane proteins, and they contain a variety of signal-transduction molecules. Both N-terminal myristoylation and palmitoylation of eNOS are necessary for optimal targeting to caveolae (117). In addition to co- and posttranslational modifications of resident proteins, membrane cholesterol is essential for normal caveolae function (118). Oxidized LDL (OxLDL) causes depletion of caveolae cholesterol in endothelial cells via the scavenger receptor CD36, leading to eNOS redistribution to an intracellular locale and an attenuated capacity to activate the enzyme $(119,120)$.

HDL maintains the total cholesterol content of caveolae by the provision of cholesterol ester, resulting in preservation of the eNOS signaling module. Based on studies of mimetics of apoA-I, HDL prevents eNOS uncoupling by LDL, which favors $\mathrm{O}_{2}$ production over NO production. HDL causes membrane-initiated signaling, which stimulates eNOS activity. Binding of HDL to SR$\mathrm{BI}$ via apoA-I causes rapid activation of the nonreceptor tyrosine kinase Src, leading to Phosphoinositide 3-kinase (PI3-kinase) activation and downstream activation of Akt kinase and MAP kinase, which result in enhancement of eNOS activity. Although the apolipoprotein and phospholipid components of HDL are sufficient to activate signaling, there may also be involvement of HDLassociated lysophospholipids SPC, S1P, and LSF acting through the lysophospholipid receptor S1P3. In addition to modulating the acute response, the activation of the PI3-kinase-Akt kinase pathway and MAP kinase by HDL causes an increase in eNOS protein (122).

Multiple proatherogenic factors promote apoptosis in endothelium, and these include OxLDL $(123,124)$, TNF- $\alpha(124,125)$, homocysteine (126), and angiotensin II (126). OxLDL causes a delayed but sustained increase in intracellular $\mathrm{Ca}_{2}{ }^{+}$in endothelial cells, which results in cell death, and this effect is reversed by HDL and mediated by prevention of the sustained $\mathrm{Ca}^{+}{ }^{+}$increase. A putative redox motif CXXS residing at amino acids 323 to 326 of SR-BI is required for the promotion of apoptosis and that this is mediated by caspase 8 , which is a component of the membrane-related apoptosis pathway. The proapoptotic effects of SR-BI were reversed by HDL and by eNOS, suggesting that under normal conditions, the antiapoptotic actions of NO prevail, whereas with low levels of HDL, 
SR-BI may promote endothelial cell death (128).

The processes of endothelial cell proliferation and migration are crucial to both neovascularization and to a successful response to vascular injury. Disruptions of endothelial cell monolayer integrity, either by gross denudation related to a vascular intervention or gap formation between cells caused by disturbed shear stress, place the arterial wall at greater risk for vascular disease (129-131). Furthermore, whereas repeated endothelial removal worsens the severity of vascular lesions (132), enhanced reendothelialization blunts lesion formation $(133,134)$. Providing another potential explanation for the cardiovascular protection afforded by HDL.

The molecular mechanisms responsible for the antithrombotic effects of HDL are likely to be multiple (135-137), and they relate to the 3 categories of processes known as Virchow's triad, which contribute to thrombus formation: (1) dysfunction of the cells within the vascular wall, particularly the endothelium; (2) disturbed blood flow; and (3) dysfunction of blood components. Many of the protective activities of HDL in the first 2 categories entail the NO-dependent ability of the lipoprotein to promote endothelial cell health and optimal vasoregulation. In addition to promoting NOproduction,HDLcausesenhanced prostacyclin synthesis, which can modify thrombosis as well as other intravascular events. Prostacyclin acts synergistically with NO to induce Vascular Smooth Muscle (VSM) relaxation, inhibit platelet activation, and diminish the release of growth factors that stimulate the local proliferation of VSM cells. The impact of HDL on prostacyclin production in endothelium occurs by both the provision of arachidonate (140-143) and upregulation of Cox-2 expression $(144,145)$. Recently, it has been shown that $\mathrm{HDL}_{3}$ induces Cox-2 expression and prostacyclin release via a p38 MAP kinase/CREB-dependent pathway in endothelium that mimics the mechanism that occurs in VSM (146-148).

HDL transports various sphingolipids that are present in plasma in the micromolar range, and at least 4 kinds of HDL sphingolipids (149) may directly or indirectly contribute antithrombotic activity. HDL may promote fibrinolysis by downregulating plasminogen activator inhibitor-I (PAI-I) and by upregulating tissue plasminogen activator (t-PA) (149-151). The oxidation of HDL alters the influence of HDL on fibrinolysis because oxidized $\mathrm{HDL}_{3}$, but not native $\mathrm{HDL}_{3}$, promotes PAI-I expression and consequently suppresses fibrinolysis (152).

Platelet aggregation is inversely correlated with HDL levels in humans (153), suggesting that HDL has antiplatelet actions. Mechanistically, although HDL may reduce platelet activation directly (154), HDL may also act indirectly on platelet activation via effects on endothelial cells.

\section{HDL Proteome}

The inverse relationship between plasma HDL-C levels and atherosclerotic CVD provides the epidemiological basis for the widely accepted hypothesis that HDL is atheroprotective. Despite intense research, the underlying mechanisms of HDL athero-protection remain incompletely understood. Indeed, recent clinical trials $(155,156)$ indicate the complexity of HDL physiology and the challenges in developing HDL therapies. HDL function, and benefit with a specific therapy, may depend more on the molecular mechanism driving increases in HDL-C than on the absolute level of HDL-C (157). Some interventions that raise HDL-C levels may have no benefit and even promote atherosclerosis (158), while other therapies may reduce CVD without actually changing HDL-C levels (155). Overall, the epidemiological evidence suggests that the majority of mechanisms that result in higher HDL-C levels in vivo will provide athero-protection; the question is how to identify such targets. This requires a shift in mindset toward assessing HDL in terms of its atheroprotective functions rather than just levels of cholesterol and its main apoprotein, APOAI.

Although several measures of HDL particles, composition, and function exist, there are no tractable methods for assessing RCT in humans, and simple, reliable, and reproducible assays of HDL anti-inflammatory functions are lacking. In this setting, recent HDL proteomic studies may provide novel insights into HDL physiology and the potential for development of bioassays of HDL function, although such studies are in their infancy $(15,159$ 162).

Shotgun proteomic analysis identified multiple complement regulatory proteins, protease inhibitors, and acute-phase response proteins in HDL, strongly implicating the lipoprotein in inflammation and the innate immune system (163).

Mass spectrometry and biochemical analyses demonstrated that $\mathrm{HDL}_{3}$ from subjects with $\mathrm{CAD}$ was selectively enriched in apoE, raising the possibility that HDL carries a unique cargo of proteins in humans with clinically significant cardiovascular disease. Collectively, these observations suggest that HDL plays previously unsuspected roles in regulating the complement system and protecting tissue from proteolysis and that the protein 
cargo of HDL contributes to its antiinflammatory and antiatherogenic properties (159).

Using shotgun proteomics, Vaisar et al. identified 48 proteins in $\mathrm{HDL}$, isolated by ultracentrifugation from healthy controls and/or CAD subjects (159). They included 22 of 23 known HDL proteins with wellcharacterized roles in lipid metabolism, which validates our experimental approach. Importantly, they found 13 proteins not previously known to reside in HDL. Surprisingly, acute-phase response proteins (23 of 48), whose plasma concentrations are altered markedly by acute inflammation (158), outnumbered proteins implicated in lipid metabolism. Several proteins not previously known to reside in HDL, including complement factors $\mathrm{C} 4 \mathrm{~A} / \mathrm{C} 4 \mathrm{~B}$ and $\mathrm{C} 9$ as well as the complement regulatory protein vitronectin, were identified. Vitronectin is an extracellular matrix protein, which raises the possibility that certain HDL components can be derived from non-cellular sources or cells distinct from those that synthesize apoA-I in the liver and intestine. The detection of multiple proteins with roles in complement activation, together with pioneering studies of HDL protein complexes that kill protozoa (164), is consistent with the suggestion that HDL serves as a platform for the assembly of proteins involved in the innate immune response. Given that proteolysis of structural proteins in atherosclerotic lesions is thought to play a critical role in plaque rupture, the major cause of myocardial infarction and sudden death in subjects with CAD (165), it is noteworthy that a family of proteins in HDL that contain serine proteinase inhibitor domains. Serine protease inhibitors, termed serpins, are key regulators of numerous biological pathways involved in inflammation, coagulation, angiogenesis, and matrix degradation. Moreover, they also detected the thiol proteinase inhibitor kininogen-1 and haptoglobin-related protein, which contains a crippled catalytic triad residue that may allow it to act as a decoy substrate to prevent proteolysis. These observations suggest that HDL plays a previously unsuspected role in preventing plaque rupture, perhaps by protecting vascular lesions from promiscuous proteolysis.

These observations support the proposal that alterations in HDL's protein cargo might boost the formation of inflammatory particles $(138,169)$, raising the possibility that quantifying those proteins could provide insights into atherogenesis. Importantly, the CAD subjects were newly diagnosed (though at least 3 months past any acute CAD event) and not on medications that alter lipid levels. Using statistical approaches based on spectral counting [the number of MS/MS spectra unique to a protein $(166,167)]$ and random permutation analysis $(159,167)$, they found five proteins that were apparently enriched in HDL isolated from the CAD subjects. These proteins related to lipid metabolism (apoE, apoC-IV, and apoA-IV), oxidative stress (paraxonase-1), and the immune system

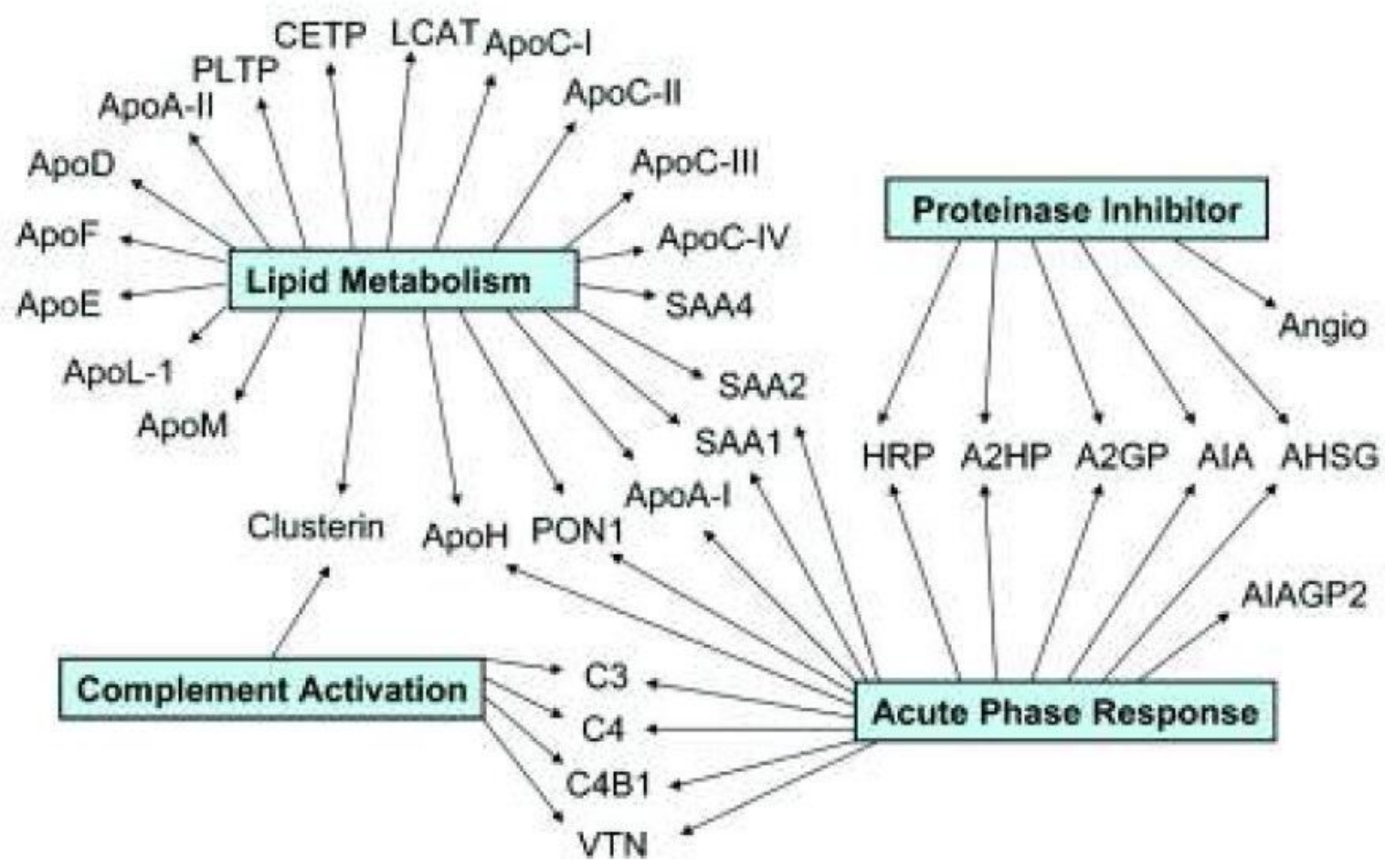

Figure 4. Global view of biological processes and molecular functions of HDL proteins (Reproduced with permission from Heinecke JW. J Lipid Res 2009: S167-S71. () American Society for Biochemistry and Molecular Biology, Inc.). 
(complement factor C3). ApoA-IV, located in the apoA-I/ apoC-III/apoA-IV gene cluster, inhibits atherosclerosis in mouse models of hypercholesterolemia (168). ApoE, apoC-IV, and C3 are expressed by macrophages $(169,170)$. C3 is needed to assemble the membrane attack complex of the complement system, suggesting a link between HDL, macrophages, and innate immunity.

Elevated levels of apoE in $\mathrm{HDL}_{3}$ isolated from two independent groups of subjects with established CAD raises the possibility that alteration in HDL's protein content serves as a marker, and perhaps a mediator, of CAD.

Proteomics studies have extended the list of identified apolipoproteins and associated proteins present in HDL and its subclasses. These proteins appear to cluster around specific functions related to lipid metabolism, inflammation, the immune system, hormone-binding, hemostasis, and antioxidant properties (171).

In moving forward, the challenge will be to develop relatively simple HDL biomarkers that can be measured before and after a clinical intervention, then correlated with clinical outcomes or atherosclerosis imaging, and ultimately used in CVD risk prediction. Examples could be an immunoassay for the content of specific proteins in HDL or its subfractions; e.g., the proportion of HDL or subclasses containing APOE, LCAT, or Lp-PLA, specific complement proteins, antiproteases, or oxidized lipids could turn out to have predictive value. Application of a broad spectrum of assays that address HDL functionality as well as composition is likely to provide the greatest insight into the relationship between HDL and atherosclerosis and the effects of novel therapies (14).

\section{HDL and $\beta$-Cell Function in T2DM}

Impaired glucose-stimulated insulin secretion is characteristic among individuals with T2DM (172), and both $\beta$-cell dysfunction and loss of $\beta$-cell mass are known to be important in the pathogenesis of T2DM (173). Changes in lipoprotein particles are evident in both metabolic syndrome and T2DM (174), and are likely to play an important role in the development of atherosclerosis. Recent data, however, suggest that changes in HLD and LDL could also influence $\beta$-cell function and mass, implying a role for lipoprotein particles in the pathogenesis of T2DM. Patients with diabetes exhibit an increase in small, dense pro-atherogenic LDL particles (174). Importantly, the diabetic dyslipidaema frequently precedes T2DM by years, suggesting that disturbances in lipid metabolism may be an early event in the development of this disease $(175,176)$. In agreement with this, low HDL is an independent risk factor for the development of T2DM (175). Furthermore, bezafibrate treatment, which raises HDL-cholesterol levels by $16 \%$ and decreases triglyceride levels by $24 \%$, reduces the incidence and delays the onset of T2DM in coronary artery disease patients with impaired fasting glucose (177).

The most common abnormality detected in HDL lipid composition in T2DM is an enrichment of triglycerides in the HDL core and a depletion in cholesterol ester (178). However, other alterations include increased SAA concentration, accumulation of glycated ApoA1 and ApoA2, changes in phospholipid composition and decreased levels of HDL-associated enzymes including PON1 and LCAT (178). As a result of these changes in composition, ApoA 1 or HDL isolated from T2DM patients has decreased cholesterol efflux capacity $(179,180)$ and defective antioxidative activity (181). Furthermore, HDL3 isolated from people with metabolic syndrome has defective antiapoptotic activity (182). Therefore, in addition to decreased absolute levels of HDL, patients with T2DM also have functionally defective HDL particles. Over the last 5 years, there have been a number of studies that point to the role of $\beta$-cell cholesterol homeostasis on insulin secretion (183).

Cholesterol can regulate signal transduction through membrane microdomains and gene expression through cholesterol-activated transcription factors (184). For example, intracellular cholesterol regulates glucose metabolism and gene expression in adipocytes (185). Glucose Stimulated Insulin Secretion (GSIS) is a complex process involving a cascade of regulatory factors. Misregulation of cholesterol could result in disruption of any one pathway and lead to partial or a near complete loss of secretory function. One potential mechanism for cholesterol regulation of GSIS that involves modification of neuronal NO synthase (nNOS) and GK activity through cholesterol-rich membrane microdomains on the insulin granules (186).

As HDLs are the predominant acceptors of cell cholesterol, it follows that they may be important for maintaining normal $\beta$-cell function and insulin secretion. Indeed, it has recently been reported that infusing supraphysiological $(80 \mathrm{mg} / \mathrm{kg})$ doses of discoidal reconstituted HDLs (rHDL) containing Apo A-I complexed with phosphatidylcholine, (A-I)rHDL, into humans with T2DM increases plasma insulin levels, reduces plasma glucose levels, and increases myocyte glucose uptake (187). The ABCAl, which exports cholesterol from $\beta$-cell membranes to lipid-free/lipid-poor apo A-I, is also 
important for maintaining normal insulin secretion and glucose tolerance in mice (188). Moreover, HDLs have been reported to inhibit $\beta$-cell apoptosis and promote $\beta$-cell survival (189-191).

Recent study showed that apoA-I and apoA-II, in either the lipid-free form or as a constituent of discoidal rHDLs, as well as HDLs from human plasma, markedly increase insulin secretion from Min6 cells and primary islets under basal and high-glucose conditions without depleting the insulin or cholesterol content of the cells. These effects, which were calcium dependent and involved expression of ABCA1, ABCG1, and SR-B1, indicate that HDLs enhance $\beta$-cell insulin secretory function (192).

Thus, abnormal cellular cholesterol handling in islets may contribute to $\beta$-cell dysfunction in T2DM. $\beta$-cell deficiency for the ABCA1, which mediates the efflux of cellular cholesterol, leads to altered intracellular cholesterol homeostasis and impaired insulin secretion in mice (193).

In addition to its effects on $\beta$-cell function, HDL has been shown to directly and positively influence $\beta$-cell survival. HDL has been shown to decrease caspase-3 cleavage (189) and downregulate the death receptor TNF receptor superfamily member 6, also known as Fas (191). In addition, inducible nitric oxide synthase (iNOS), which is known to mediate the proapoptotic effects of glucose and cytokines is downregulated by HDL treatment (191).

In addition, the antioxidative activity of HDL is decreased in T2DM (181), which could limit its ability to prevent oxLDL-induced $\beta$-cell death in T2DM. These data suggest that diabetic dyslipidaemia could potentially contribute to the loss of $\beta$-cell mass in T2DM. The insulin resistance associated with metabolic syndrome and low HDL may progress to frank diabetes. Is it possible that apoprotein-stimulated insulin secretion is attenuated during this progression? First, the stimulation of insulin secretion is apoprotein concentration dependent over a physiologically relevant range. So with low HDL in vivo, especially if this HDL is dysfunctional, as is likely the case in diabetes and the metabolic syndrome, the optimal cofactors for insulin secretion and compensatory function of the $\beta$-cell may be limited. Furthermore, in the prediabetic and diabetic state, many proteins may become glycated or modified by carbonyls derived from carbohydrate oxidation, such as glycolaldehyde, glyoxal, and methylglyoxal. ApoA-I modified by these carbonyls is still able to mediate ABCA1-dependent cholesterol efflux (194). However, these carbohydrate-derived aldehydes have the capacity to influence $\mathrm{ABCA} 1$ function and particularly stabilization so that the functioning of this interacting couple of proteins may well be impaired in diabetes or prediabetes (195).

Therapeutic normalization of both the quantity and quality of HDL particles in patients with T2DM may provide a unique approach to promote $\beta$-cell survival and function and to decrease islet inflammation. HDL could thus represent a new therapeutic target in T2DM (196).

\section{HDL and Aging Process}

HDL plasma concentrations decline with age in prospective studies. Decline in HDL concentration and function may occur secondary because of hormonal changes, inflammatory processes, and diabetes mellitus. Beyond these effects specific aging processes may be involved. Replicative aging, the telomere-driven loss of divisional capacity, is a species-specific aging mechanism that may decrease HDL concentration and function. Vice versa, HDL may modulate the aging process, not only by its wellknown antiatherogenic effects, eg, its ability to remove cellular lipids and by antiatherogenic pleiotropic effects on cell survival, but possibly also by direct interfering with aging signaling or survival factor KLOTHO.

Aging is a complex process that (on the cellular level) includes cell cycle arrest, morphology remodeling with functional decline, chromatin silencing with profound gene expression changes, and changes in metabolism. Different triggers may act together in a cooperative fashion and use overlapping signaling pathways to induce and propagate the aging process (198). Replicative aging results from the progressive shortening of telomeres (composed of conserved nucleotide sequences, TTAGGG in vertebrates) attributable to incomplete end replication during cell divisions. It may protect against increased cancer risk but may also contribute to atherosclerosis in later life, particularly at "atherosclerosis-prone areas" with high replication rates (199).

The KLOTHO gene, identified by insertional mutagenesis in mice, is a suppressor of the expression of multiple aging phenotypes, including atherosclerosis (200). Antiaging properties of the shed transmembrane form of KLOTHO protein are mostly explained by its hormonal effect on insulin signaling: KLOTHO moderately inhibits insulin/IGF1 signaling, which is the only proven evolutionary conserved mechanism for life span extension in men.

HDL cholesterol levels are inversely associated with the detrimental effect of a dysfunctional KLOTHO protein in humans. HDL cholesterol levels in the high normal range seem to be completely protective against KLOTHO dysfunction $(201,202)$. The underlying mechanism of this 
relationship is unknown. It is obvious, however, that HDL and KLOTHO modulate similar signaling pathways. Both molecules induce NO synthesis, counteract apoptosis, induce angiogenesis, and counteract insulin signaling in cell culture models $(200,203,204)$. Several mechanisms may be involved to explain a functional interrelationship between KLOTHO and HDL. HDL may compensate for KLOTHO dysfunction by its ability to remove cellular lipids. One recently proposed model is that the main antiaging effect of KLOTHO is its ability to prevent cellular lipid overload (and lipoapoptosis) by reducing insulin-stimulated availability of the lipogenic substrate glucose (205). Future studies are required to find strategies to mimic the positive (antiaging) effects of HDL and to prevent the negative effects of aging on HDL (197).

\section{HDL and Hematopoietic Stem Cell Proliferation}

Yvan-Charvet $e t$ al. present an entirely new role for HDL in regulating stem cell proliferation in the bone marrow (206). A relationship between cellular cholesterol content, HDL, and cells of the myelomonocytic lineage opens up the possibility that disorders characterized by the proliferation of immature white blood cells could be treated by targeting cholesterol transport in these cells. Many cell surface receptors assemble in membrane "rafts" that contain a high content of cholesterol and glycolipids. These rafts enhance receptor oligomerization and signaling in many cell types (207). In hematopoietic progenitor stem cells, growth factor receptors are organized in lipid rafts to promote receptor signaling and consequently, cell proliferation and migration (208). Because cholesterol overload can cause havoc in cells, its concentration is regulated by several mechanisms. Excess cholesterol is removed by ATP binding cassette $(\mathrm{ABC})$ transporters in the plasma membrane, which move cholesterol to extracellular HDL particles at the cell surface (6).

As hematopoietic growth factor receptors in stem cells organize in membrane rafts, the availability of cholesterol for raft formation modulates receptor function. Membrane cholesterol can come either from lipoprotein uptake or local synthesis in the cell and is balanced by elimination of cholesterol from the cell. This balance depends on ABCA1 and $\mathrm{ABCG} 1$ transporters that mobilize cholesterol from the membrane, and on HDL particles that act as cholesterol acceptors. Lack of ABCA1 and ABCG1 results in increased raft formation, whereas addition of HDL reduces rafts.
Increased raft formation helps to cluster receptors for IL-3 and GM-CSF, leading to increased responsiveness to these hematopoietic growth factors and to increased proliferation of myeloid precursor cells $(209,210)$.

In atherosclerosis, leukocytosis is observed (211), but the reason has been unclear. The results of Yvan-Charvet $e t$ $a l$. suggest that individuals with hypercholesterolemia may develop leukocytosis because of increased proliferation of myeloid progenitors in the bone marrow. Again, the cholesterol efflux pathway could be an interesting target for therapy (212).

\section{HDL, Apo-A1 Mimetics and LXR Agonist}

Emerging evidence suggests that HDL function is not always accurately predicted by HDL cholesterol levels. The functions of HDL include reverse cholesterol transport and modulation of inflammation. These functions appear to have evolved as part of the innate immune system. HDL may be thought of as a shuttle. The size of the shuttle can be estimated by HDL cholesterol levels. The shuttle's cargo can change dramatically from one that efficiently promotes reverse cholesterol transport and is anti-inflammatory to one that is less effective in promoting reverse cholesterol transport and is also proinflammatory without any change in the size of the shuttle (i.e., these changes in HDL cargo can occur without any change in HDL cholesterol levels). Understanding these issues may lead to improved use of HDL as a biomarker and may also lead to new therapeutic targets and therapies (213).

Measuring HDL cholesterol levels may not accurately predict the composition, functionality, and anti-inflammatory properties of HDL. HDL in diseases associated with a chronic acute-phase response has been found to be dysfunctional and proinflammatory. Currently, there are no tests widely available for measuring the composition, functionality, and inflammatory properties of HDL in clinical practice. However, it appears that the composition, functionality, and inflammatory properties of HDL are directly related to the presence or absence of conditions that are known to induce a chronic acute-phase response. These conditions are clinically recognizable (e.g., diabetes, visceral obesity, CHD, rheumatic diseases, chronic inflammatory gastrointestinal conditions, chronic renal disease, and chronic infections) (213).

Simply increasing the amount of circulating HDLcholesterol does not reduce the risk of coronary heart 
disease (CHD) events, CHD deaths, or total deaths (214). Singh et al. (215) suggested that HDL could be a therapeutic target by modifying its lipid and protein cargo to improve its antiinflammatory properties. One method that has been reported to modify the lipid and protein cargo of HDL involves treatment with apolipoprotein mimetic peptides (216).

HDL mimetics have been constructed from a number of peptides and proteins with varying structures, all of which bind lipids found in HDL. HDL mimetics containing a peptide or protein have been constructed with as few as 4 and as many as 243 amino acid residues. Some HDL mimetics have been constructed with lipid but without a peptide or protein component. Some HDL mimetics promote cholesterol efflux, some have been shown to have a remarkable ability to bind oxidized lipids compared to human apoA-I. Many of these peptides have been shown to have antiinflammatory properties. Based on studies in a number of animal models and in early human clinical trials, HDL mimetics appear to have promise as diagnostic and therapeutic agents (217).

Use of apo A-I mimetic peptides could potentially overcome some of the limitations associated with use of the intact apo. Studies to establish the most efficacious peptides, optimal dosing regimens, and routes of administration are needed. Use of apo A-I mimetic peptides shows great promise as a therapeutic modality for HDL replacement and enhancing HDL function in treatment of patients with CHD (218).

ApoA-I mimetic peptides show remarkable capacity to support cholesterol efflux, share the antiinflammatory properties of HDL, and reduce development of atherosclerosis in animal models $(110,219-222)$. ApoA-I mimetic peptides cost a fraction of the cost of reconstituted HDL; they are safe and well tolerated (223), and approaches for oral delivery are being developed $(220,224)$. Perhaps the best advantage of these peptides is the ability to modify their structure to better understand the mechanisms of atheroprotective action of HDL, with a view to further improving the atheroprotective capacity of the peptides (225).

Dysfunctional HDL has been identified in animal models and humans with chronic inflammatory diseases including atherosclerosis. The loss of antiinflammatory function correlated with a loss of function in reverse cholesterol transport. In animal models and perhaps in humans, dysfunctional HDL can be improved by apoA-I mimetic peptides that bind oxidized lipids with high affinity.

ApoA-I peptide mimetic removed seeding molecules from human LDL, rendering the LDL resistant to oxidation by human artery wall cells. The apoA-I-associated seeding molecules included hydroperoxyoctadecadienoic acid (HPODE) and hydroperoxyeicosatetraenoic acid (HPETE) (12).

It is now generally accepted that HDL and its apolipoproteins are the major initial acceptors of excess cellular cholesterol. Members of the ABC transporter family have been identified as key, and potentially complementary, cellular participants in export of cholesterol to these acceptors. ABCAl mediates cholesterol efflux most efficiently to lipid-poor apoAI, whereas ABCG1 promotes cholesterol export to lipidated particles such as HDL. In addition, the SR-BI receptor pathway can also promote cholesterol export to HDL particles (226).

The liver $\mathrm{X}$ receptors, LXRs, are nuclear receptors that act as cholesterol sensors in controlling transcription of genes involved in cholesterol homeostasis and lipid metabolism. LXR agonists have been demonstrated to delay atherosclerosis in mice (227) by stimulating reverse cholesterol transport from macrophages. Additional studies have revealed that expression of LXR in macrophages is a prerequisite for the atheroprotective effect of LXR (228). Because ABCG1 and ABCAl gene expression is stimulated by LXR agonists in human macrophages (229), upregulation of macrophage ABCG1 and ABCA1 by LXR agonists may constitute an effective pharmacological approach to attenuate foam cell formation, and thereby to prevent arterial lipid accumulation and lesion progression in dyslipidemic patients.

Coffee and green tea are a major source of polyphenols (231), a group of compounds that has received substantial interest in recent years. The term polyphenol represents a wide variety of compounds derived from plants, and polyphenols are present in many components of the human $\operatorname{diet}(232)$.

Polyphenol-rich foods have previously been associated with decreased risk of cardiovascular disease in multiple studies (233). Interestingly, certain polyphenols, such as resveratrol and anthocyanins (both found in red wine among other sources), have been shown to increase macrophage cholesterol efflux ex vivo (234-236).

Uto-Kondo et al., describe a careful series of experiments that tested the hypothesis that polyphenols found in coffee or green tea may promote macrophage cholesterol efflux (237). The authors focused their study on caffeic and ferulic acids, phenolic acids (a subclass of polyphenols) known to be present in coffee and green tea and increased in plasma by coffee consumption (238). Importantly, both compounds increased HDLmediated cholesterol efflux in vitro in a dose-dependent fashion via enhanced expression of the ABCG1 (and SR- 


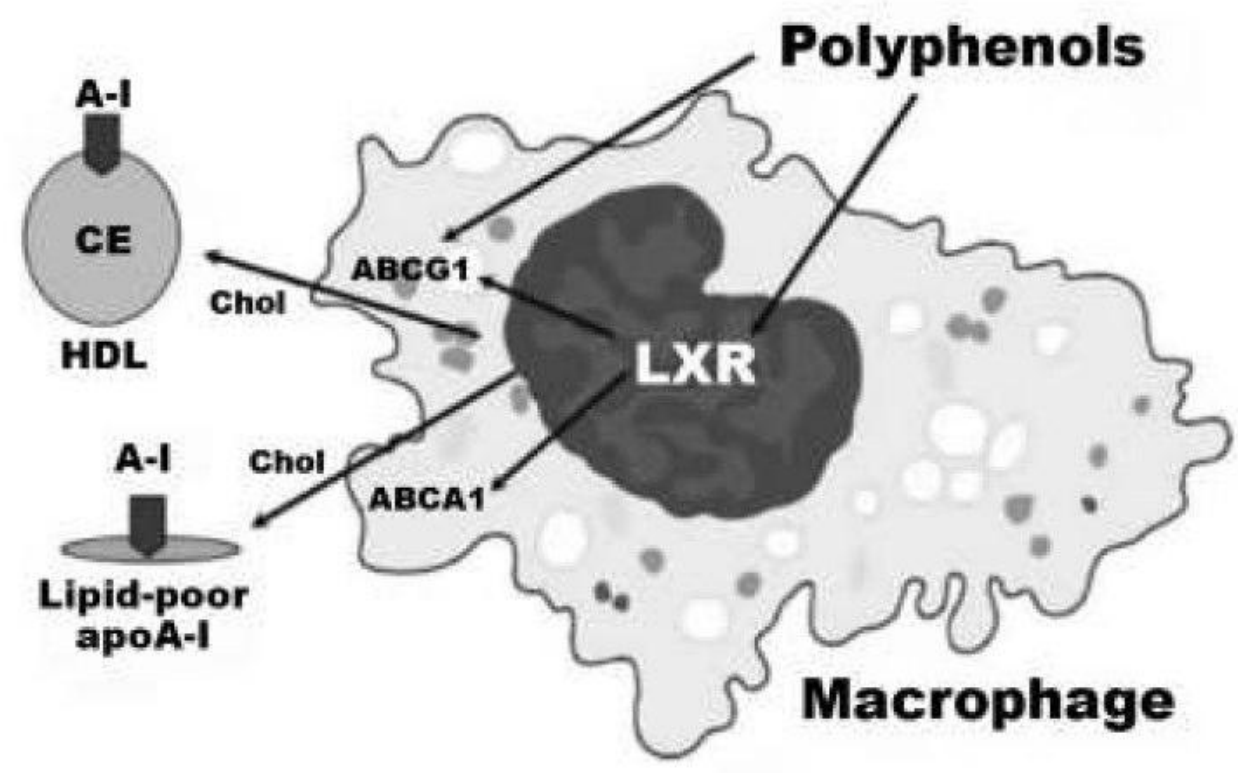

Figure 5. Postulated mechanisms for effects of polyphenols on macrophages cholesterol efflux (Reproduced with permission from Burke MF, Khera AV, Rader DJ. Polyphenols and cholesterol efflux. Circ Res 2010; 106: 627-9. (c) American Heart Association).

BI) transporters. Ferulic acid, but not coffee itself, was additionally shown to modestly enhance macrophage RCT in vivo in mice.

Uto-Kondo et al. provide a useful methodologic framework for studies that explore the association between various compounds and cholesterol efflux. Their work adds to a growing body of evidence that suggests a role for polyphenols in cellular cholesterol efflux. If confirmed, this conceptual approach to enhancement of macrophage RCT flux could prove valuable in the prevention and treatment of cardiovascular disease in humans (230).

\section{Conclusion}

HDL has many other activities aside from its role in RCT that can also contribute to its protective mechanism. These include the removal or detoxification of oxidized sterols and phospholipids, anti-inflammatory activity, antioxidant activity, antithrombotic activity, and its protective and healing activities on endothelial cells.

Proteomic analysis indicate that HDL carries a population of proteins that function in lipid metabolism, proteinase inhibition, complement activation, and the acute-phase response. Raising the possibility that these proteins contribute to the innate immune system and the cardioprotective properties of HDL.
Synthetic high-density lipoprotein (HDL) and apolipoprotein (apo) A-I mimetic peptides emulate many of the atheroprotective biological functions attributed to HDL and can modify atherosclerotic disease processes. Administration of these agents as HDL replacement or modifying therapy has tremendous potential of providing new treatments for cardiovascular disease.

We will ultimately determine how to take optimal advantage of the potent cardiovascular protective properties of HDL for prophylactic and therapeutic benefit.

\section{References:}

1. Ashen MD, Blumenthal RS. Clinical practice. Low HDL cholesterol levels. N Engl J Med. 2005; 353: 1252-60.

2. Barter PJ, Caulfield M, Eriksson M, et al. Effects of torcetrapib in patients at high risk for coronary events. N Engl J Med. 2007;357:2109-22.

3. Rader DJ. Illuminating HDL-is it still a viable therapeutic target? N Engl J Med. 2007;357:2180-3.

4. deGoma EM, deGoma RL, Rader DJ. Beyond high-density lipoprotein cholesterol levels evaluating high-density lipoprotein function as influenced by novel therapeutic approaches. J Am Coll Cardiol. 2008;51: 2199-211.

5. Rothblat GH, Philips MC. High-density lipoprotein heterogeneity and function in reverse cholesterol transport. Curr Opin Lipidol 2010; 21: 229-38.

6. Tall AR. Cholesterol efflux pathways and other potential mechanisms involved in the athero-protective effect of high density lipoproteins. J Internal Med 2008; 263:256-73.

7. Yvan-Charvet L, Wang N, Tall AR. Role of HDL, ABCA1, and ABCG1 transporters in cholesterol efflux and immune 
responses. Arterioscler Thromb Vasc Biol 2010; 30:13943.

8. Tabet F, Rye K-A. High-density lipoproteins, inflammation and oxidative stress. Clin Sci 2009; 116:87-98.

9. Nicholls SJ, Nissen SE. New targets of high-density lipoprotein therapy. Curr Opin Lipidol 2007; 18:421-6.

10. von Eckardstein A, Nofer J-R, Assmann G. High density lipoproteins and apolipoproteins. Role of cholesterol efflux and reverse cholesterol transport. Arterioscler Thromb Vasc Biol 2001; 21:13-27.

11. Movva R, Rader DJ. Laboratory assessment of HDL heterogeneity and function. Clin Chem 2008; 54:788-800.

12. Navab M, Reddy ST, Van Lenten BJ, et al. The role of dysfunctional HDL in atherosclerosis. J Lipid Res 2009; 50:S145-9.

13. Smith JD. Dysfunctional HDL as a diagnostic and therapeutic target. Arterioscler Thromb Vasc Biol 2010; 30:151-5.

14. Reilly MP, Tall AR. HDL proteomics: pot of gold or Pandora's box? J. Clin. Invest. 2007; 117: 595-8.

15. Hortin GL, Shen RF, Martin BM, Remaley AT. Diverse range of small peptides associated with highdensity lipoprotein Biochem. Biophys. Res. Commun. 2006; 340: 909-15.

16. Scanu AM, Edelstein C, HDL: bridging past and present with a look at the future. FASEB J 2008; 22: 4044-54.

17. Cavigiolio G, Shao B, Geier EG, Ren G, Heinecke JW, Oda MN. The interplay between size, morphology, stability, and functionally of High - Density Lipoprotein subclasses. Biochemistry 2008; 47: 4770-9.

18. Nichols AV, Krauss RM, Musliner TA. Nondenaturing polyacrylamide gradient gel electrophoresis. Methods Enzymol 1986; 128:417-31.

19. Kunitake ST, La Sala KJ, Kane JP. Apolipoprotein A-I-containing lipoproteins with prebeta electrophoretic mobility. J Lipid Res 1985; 26:549-55.

20. Castro GR, Fielding CJ. Early incorporation of cell-derived cholesterol into prebeta-migrating high-density lipoprotein. Biochemistry 1988; 27:25-9.

21. Skipski VP. Lipid composition of lipoproteins in normal and diseased states. In: Nelson GJ, editor. Blood lipids and lipoproteins: quantitation composition, and metabolism. New York: Wiley-Interscience; 1972. pp. 471-583.

22. Fielding CJ, Fielding PE. Molecular physiology of reverse cholesterol transport. J Lipid Res 1995; 36:211-28.

23. Mulya A, Seo J, Brown AL, et al. Apolipoprotein M expression increases the size of nascent prebeta HDL formed by ATP binding cassette transporter A1 (ABCA1). J Lipid Res 2010; 51: $514-24$

24. Krimbou L, Hassan $\mathrm{HH}$, Blain $\mathrm{S}$, et al. Biogenesis and speciation of nascent apoA-1-containing particles in various cell lines. $J$ Lipid Res 2005; 46: 1668-77.

25. Lagor WR, Brown RJ, Toh SA, et al. Overexpression of Apolipoprotein $\mathrm{F}$ reduces $\mathrm{HDL}$ cholesterol levels in vivo. Arterioscler Thromb Vasc Biol 2009; 29: 40-6.

26. Jonas A, Phillips MC. Lipoprotein structure. In: Vance DE, Vance JE, editors. Biochemistry of lipids, lipoproteins and membranes. Elsevier; 2008. pp. 485-506.

27. Shen BW, Scanu AM, Kezdy FJ. Structure of human serumlipoproteins inferred from compositional analysis. Proc Natl Acad Sci USA 1977; 74:837-41.

28. Rye KA, Barter PJ. Formation and metabolism of prebetamigrating, lipid-poor apolipoprotein A-I. Arterioscler Thromb Vasc Biol 2004; 24:421-8.

29. Rothblat GH, de la Llera-Moya M, Atger V, Kellner-Weibel G, Williams DL, Phillips MC. Cell cholesterol efflux: integration of old and new observations provides new insights. J Lipid Res 1999; 40: 781-96.

30. Chirinos JA, Zambrano JP, Chakko S, et al. Ability of serum to decrease cellular acylCoA:cholesterol acyl transferase activity predicts CV outcomes. Circulation 2005; 112: 244653.

31. Matsuura F, Wang N, Chen W, Jiang XC, Tall AR. HDL from CETP-deficient subjects shows enhanced ability to promote cholesterol efflux from macrophages in an apoEand ABCG1-dependent pathway. J Clin Invest 2006; 116: 1435-42.

32. Wang X, Rader DJ. Molecular regulation of macrophage reverse cholesterol transport. Curr Opin Cardiol. 2007; 22: 368-72.

33. Cuchel M, Rader DJ. Macrophage reverse cholesterol transport: key to the regression of atherosclerosis? Circulation. 2006; 113: $2548-55$

34. Rader DJ. Regulation of reverse cholesterol transport and clinical implications. Am J Cardiol. 2003; 92: 42J-9J.

35. Majeed F, Miller M. Low high-density lipoprotein cholesterol: an important consideration in coronary heart disease risk assessment. Curr Opin Endocrinol Diabetes Obes 2008; 15: $175-81$.

36. Gordon TCW, Hjortland MC, et al. High density lipoprotein as a protective factor against coronary heart disease. The Framingham Study. Am J Med 1977; 62: 707-14.

37. Pearson H. When good cholesterol turns bad. Nature 2006; 444: 794-5.

38. Nissen SE, Tardif JC, Nicholls SJ, et al. Effect of torcetrapib on the progression of coronary atherosclerosis. N Engl J Med 2007; 356:1304-16.

39. Barkowski RS, Frishman WH. HDL metabolism and CETP inhibition. Cardiol Rev 2008; 16: 154-62.

40. Feng $\mathrm{H}$, LiXA. Dysfunctional high-density lipoprotein. Curr Opin Endocrinol Diabetes Obes 2009; 16: 156-62.

41. Navab M, Hama SY, Anantharamaiah GM, et al. Normal high density lipoprotein inhibits three steps in the formation of mildly oxidized low density lipoprotein: steps 2 and 3 . J Lipid Res. 2000; 41: 1495-508.

42. AnsellBJ, NavabM, HamaS, etal. Inflammatory/anti inflammatory properties of high-density lipoprotein distinguish patients from control subjects better than high-density lipoprotein cholesterol levels and are favorably affected by simvastatin treatment. Circulation. 2003; 108: 2751-6.

43. Cockerill GW, Rye KA, Gamble JR, Vadas MA, Barter PJ. Highdensity lipoproteins inhibit cytokine-induced expression of endothelial cell adhesion molecules. Arterioscler Thromb Vasc Biol. 1995; 15: 1987-94.

44. Van Lenten BJ, Wagner AC, Nayak DP, Hama S, Navab M, Fogelman AM. High-density lipoprotein loses its antiinflammatory properties during acute influenza a infection. Circulation. 2001; 103: 2283-8.

45. Castellani LW, Navab M, Van Lenten BJ, et al. Overexpression of apolipoprotein All in transgenic mice converts high density lipoproteins to proinflammatory particles. J Clin Invest. 1997; 100: 464-74.

46. Van Lenten BJ, Hama SY, de Beer FC, et al. Anti-inflammatory HDL becomes pro-inflammatory during the acute phase response. Loss of protective effect of $\mathrm{HDL}$ against LDL oxidation in aortic wall cell cocultures. J Clin Invest. 1995; 96: 275867.

47. Cabana VG, Siegel JN, Sabesin SM. Effects of the acute phase response on the concentration and density distribution of plasma lipids and apolipoproteins. J Lipid Res. 1989; 30: $39-49$.

48. Menschikowski M, Hagelgans A, Siegert G. Secretory phospholipase A2 of group IIA: is it an offensive or a defensive player during atherosclerosis and other inflammatory diseases? Prostaglandins Other Lipid Mediat. 2006; 79: 1-33.

49. Coetzee GA, Strachan AF, van der Westhuyzen DR, Hoppe $\mathrm{HC}$, Jeenah MS, de Beer FC. Serum amyloid A-containing 
human high density lipoprotein 3. Density, size, and apolipoprotein composition. J Biol Chem. 1986; 261: 9644 -51 .

50. de Beer FC, de Beer MC, van der Westhuyzen DR, Castellani LW, Lusis AJ, Swanson ME, Grass DS. Secretory nonpancreatic phospholipase A2: influence on lipoprotein metabolism. J Lipid Res. 1997; 38: 2232-9.

51. Barter PJ. Hugh sinclair lecture: the regulation and remodelling of HDL by plasma factors. Atheroscler Suppl. 2002; 3: 3947.

52. Rye KA, Hime NJ, Barter PJ. The influence of cholesteryl ester transfer protein on the composition, size, and structure of spherical, reconstituted high density lipoproteins. J Biol Chem. 1995; 270: 189-96.

53. Lewis GF, Rader DJ. New insights into the regulation of HDL metabolism and reverse cholesterol transport. Circ Res. 2005; 96: 1221-32.

54. Rye KA, Duong MN. Influence of phospholipid depletion on the size, structure, and remodeling of reconstituted high density lipoproteins. J Lipid Res. 2000; 41: 1640-50.

55. Tam SP, Ancsin JB, Tan R, Kisilevsky R. Peptides derived from serum amyloid $A$ prevent, and reverse, aortic lipid lesions in apoE-/-mice. J Lipid Res. 2005; 46: 2091-101.

56. Bowry VW, Stanley KK, Stocker R. High density lipoprotein is the major carrier of lipid hydroperoxides in human blood plasma from fasting donors. Proc Natl Acad Sci USA. 1992;89:10316-20.

57. McPherson PA, Young IS, McKibben B, McEneny J. High density lipoprotein subfractions: isolation, composition, and their duplicitous role in oxidation. J Lipid Res. 2007;48:86-95.

58. Lowensteinv CJ, Cameron SJ. High-density lipoprotein metabolism and endothelial function. Curr Opin Endocrinol Diabetes Obes 2010; 17: 166-70.

59. DaughertyA, DunnJL, Rateri DL, HeineckeJW. Myeloperoxidase, a catalyst for lipoprotein oxidation, is expressed in human atherosclerotic lesions. J Clin Invest. 1994;94:437-44.

60. Bergt C, Reicher H, Malle E, Sattler W. Hypochlorite modification of high density lipoprotein: effects on cholesterol efflux from J774 macrophages. FEBS Lett. 1999;452:295-300.

61. Panzenboeck $\mathrm{U}$, Raitmayer $\mathrm{S}$, Reicher $\mathrm{H}$, et al. Effects of reagent and enzymatically generated hypochlorite on physicochemical and metabolic properties of high density lipoproteins. J Biol Chem. 1997; 272: 29711-20.

62. Zheng L, Nukuna B, Brennan ML, et al. Apolipoprotein A-I is a selective target for myeloperoxidase-catalyzed oxidation and functional impairment in subjects with cardiovascular disease. J Clin Invest. 2004; 114: 529-41.

63. Bergt C, Pennathur S, Fu X, et al. The myeloperoxidase product hypochlorous acid oxidizes HDL in the human artery wall and impairs ABCA1-dependent cholesterol transport. Proc Natl Acad Sci USA. 2004; 101: 13032-7.

64. Pennathur S, Bergt C, Shao B, et al. Human atherosclerotic intima and blood of patients with established coronary artery disease contain high density lipoprotein damaged by reactive nitrogen species. J Biol Chem. 2004; 279: 4297783.

65. Zheng L, Settle M, Brubaker G, et al. Localization of nitration and chlorination sites on apolipoprotein A-I catalyzed by myeloperoxidase in human atheroma and associated oxidative impairment in ABCA1-dependent cholesterol efflux from macrophages. J Biol Chem. 2005; 280: 38-47.

66. Shao B, Bergt C, Fu X, et al. Tyrosine 192 in apolipoprotein A-I Is the major site of nitration and chlorination by myeloperoxidase, but only chlorination markedly impairs ABCA1-dependent cholesterol transport. J Biol Chem. 2005; 280: 5983-93.

67. Bergt C, Fu X, Huq NP, Kao J, Heinecke JW. Lysine residues direct the chlorination of tyrosines in YXXK motifs of apolipoprotein A-I when hypochlorous acid oxidizes high density lipoprotein. J Biol Chem. 2004; 279: 7856-66.

68. Peng DQ, Brubaker G, Wu Z, et al. Apolipoprotein A-I tryptophan substitution leads to resistance to myeloperoxidasemediated loss of function. Arterioscler Thromb Vasc Biol. 2008; 28: 2063-70.

69. McGillicuddy FC, de la Llera Moya M, Hinkle CC, et al. Inflammation impairs reverse cholesterol transport in vivo. Circulation 2009; 119: 1135-45.

70. Hansson GK. Inflammation, atherosclerosis, and coronary artery disease. N Engl J Med. 2005; 352: 1685-95.

71. Ley K, Laudanna C, Cybulsky MI, Nourshargh S. Getting to the site of inflammation: the leukocyte adhesion cascade updated. Nat Rev Immunol. 2007; 7: 678-89.

72. Libby P, Geng YJ, Aikawa M, et al. Macrophages and atherosclerotic plaque stability. Curr Opin Lipidol 1996; 7 : $330-5$.

73. Tabas I. Apoptosis and plaque destabilization in atherosclerosis: the role of macrophage apoptosis induced by cholesterol. Cell Death Differ 2004; 11(Suppl 1): S12-6.

74. Tabas I. Consequences and therapeutic implications of macrophage apoptosis in atherosclerosis: the importance of lesion stage and phagocytic efficiency. Arterioscler Thromb Vasc Biol 2005; 25: 2255-64.

75. Wang J, Sun F, Zhang DW et al. Sterol transfer by ABCG5 and ABCG8: in vitro assay and reconstitution. J Biol Chem 2006; 281: 27894-904.

76. Terasaka N, Wang N, Yvan-Charvet L, Tall AR. HDL protects macrophages from oxidized LDL-induced apoptosis by promoting efflux of 7-ketocholesterol via ABCG1. Proc Natl Acad Sci USA. 2007; 104: 15093-8.

77. O'Connell BJ, Denis M, Genest J. Cellular physiology of cholesterol efflux in vascular endothelial cells. Circulation 2004; 110: 2881-8.

78. Laufs U, La Fata V, Plutzky J, Liao JK. Upregulation of endothelial nitric oxide synthase by HMG COA reductase inhibitors. Circulation 1998; 97: 1129-35.

79. Gerbod-Giannone MC, Li Y, Holleboom A et al. TNFa induces ABCA1 through NF-kappaB in macrophages and in phagocytes ingesting apoptotic cells. Proc Natl Acad Sci USA 2006; 103: 3112-7.

80. Cui D, Thorp E, Li Y et al. Pivotal advance: macrophages become resistant to cholesterol-induced death after phagocytosis of apoptotic cells. J Leukoc Biol 2007; 82: 1040-50.

81. Flegel WA, Baumstark MW, Weinstock C, Berg A, Northoff $\mathrm{H}$. Prevention of endotoxin-induced monokine release by human low-and high-density lipoproteins and by apolipoprotein A-I. Infect Immun. 1993; 61: 5140-6.

82. Parker TS, Levine DM, Chang JC, Laxer J, Coffin CC, Rubin AL. Reconstituted high-density lipoprotein neutralizes gramnegative bacterial lipopolysaccharides in human whole blood. Infect Immun. 1995; 63: 253-8.

83. Takeda K, Akira S. Toll-like receptors in innate immunity. Int Immunol. 2005; 17: 1-14.

84. Moudry R, Spycher MO, Doran JE. Reconstituted high density lipoprotein modulates adherence of polymorphonuclear leukocytes to human endothelial cells. Shock. 1997; 7: 175-81.

85. Forte TM, Oda MN, Knoff L, et al. Targeted disruption of the murine lecithin:cholesterol acyltransferase gene is associated with reductions in plasma paraoxonase and platelet-activating factor acetylhydrolase activities but not in apolipoprotein J concentration. J Lipid Res. 1999; 40: 1276-83.

86. Ng CJ, Shih DM, Hama SY, Villa N, Navab M, Reddy ST. The paraoxonase gene family and atherosclerosis. Free Radical Biol Med. 2005; 38: 153-63.

87. Stocker R, Keaney JF Jr. Role of oxidative modifications in atherosclerosis. Physiol Rev 2004; 84: 1381-478. 
88. Navab M, Ananthramaiah GM, Reddy ST, et al. The oxidation hypothesis of atherogenesis: the role of oxidized phospholipids and HDL. J Lipid Res 2004; 45: 993-1007.

89. Garner B, Waldeck AR, Witting PK, et al. Oxidation of high density lipoproteins. II. Evidence for direct reduction of lipid hydroperoxides by methionine residues of apolipoproteins Al and All. J Biol Chem 1998; 273: 6088-95.

90. Panzenbock U, Stocker R. Formation of methionine sulfoxidecontaining specific forms of oxidized high-density lipoproteins. Biochim Biophys Acta 2005; 1703: 171-81.

91. Miyata M, Smith JD. Apolipoprotein E allele-specific antioxidant activity and effects on cytotoxicity by oxidative insults and beta-amyloid peptides. Nat Genet 1996; 14: 55-61.

92. Thorngate FE, Rudel LL, Walzem RL, Williams DL. Low levels of extrahepatic nonmacrophage ApoE inhibit atherosclerosis without correcting hypercholesterolemia in ApoE-deficient mice. Arterioscler Thromb Vasc Biol 2000; 20: 1939-45.

93. Tangirala RK, Pratico D, FitzGerald GA, et al. Reduction of isoprostanes and regression of advanced atherosclerosis by apolipoprotein E. J Biol Chem 2001; 276: 261-6.

94. Raffai RL, Loeb SM, Weisgraber KH. Apolipoprotein E promotes the regression of atherosclerosis independently of lowering plasma cholesterol levels. Arterioscler Thromb Vasc Biol 2005; 25: 436-41.

95. Jordan-Starck TC, Witte DP, Aronow BJ, Harmony JA. Apolipoprotein J: a membrane policeman? Curr Opin Lipidol 1992; 1992: 75-85.

96. Boisfer E, Stengel D, Pastier D, et al. Antioxidant properties of $\mathrm{HDL}$ in transgenic mice overexpressing human apolipoprotein A-II. J Lipid Res 2002; 43: 732-41.

97. Ribas V, Sanchez-Quesada JL, Anton R, et al. Human apolipoprotein A-II enrichment displaces paraoxonase from HDL and impairs its antioxidant properties: a new mechanism linking HDL protein composition and antiatherogenic potential. Circ Res 2004; $95: 789-97$.

98. Kontush A, Chapman MJ. Antiatherogenic small, dense HDL guardian angel of the arterial wall? Nat Clin Pract Cardiovasc Med 2006; 3: 144-53.

99. Kontush A, Chapman MJ. Functionally defective HDL: a new therapeutic target at the crossroads of dyslipidemia, inflammation and atherosclerosis. Pharmacol Rev 2006; 3 : 342-74.

100. Durrington PN, Mackness B, Mackness MI. Paraoxonase and atherosclerosis. Arterioscler Thromb Vasc Biol 2001; 21:473-80.

101. Christison JK, Rye KA, Stocker R. Exchange of oxidized cholesteryl linoleate between LDL and HDL mediated by cholesteryl ester transfer protein. J Lipid Res 1995; 36: 2017-26.

102. Girotti AW. Translocation as a means of disseminating lipid hydroperoxide-induced oxidative damage and effector action. Free Radic Biol Med 2008; 44: 956-68.

103. Zerrad-Saadi A, Therond P, Chantepie S, et al. HDL3-mediated inactivation of LDL-associated phospholipid hydroperoxides is determined by the redox status of apolipoprotein A-I and HDL particle surface lipid rigidity: relevance to inflammation and atherogenesis. Arterioscler Thromb Vasc Biol 2009; 29: 2169-75.

104. Proudfoot JM, Barden AE, Loke WM, et al. HDL is the major lipoprotein carrier of plasma F2-isoprostanes. J Lipid Res 2009; 50: 716-22.

105. Davidson WS, Silva RA, Chantepie $S$, et al. Proteomic analysis of defined HDL subpopulations reveals particle-specific protein clusters: relevance to antioxidative function. Arterioscler Thromb Vasc Biol 2009; 29: 870-6.

106. Kontush A, Therond P, Zerrad A, et al. Preferential sphingosine1-phosphate enrichment and sphingomyelin depletion are key features of small dense HDL3 particles: relevance to antiapoptotic and antioxidative activities. Arterioscler
Thromb Vasc Biol 2007; 27: 1843-9.

107. Kontush A, Chantepie S, Chapman MJ. Small, dense HDL particles exert potent protection of atherogenic LDL against oxidative stress. Arterioscler Thromb Vasc Biol 2003; 23: 1881-8.

108. De Souza JA, Vindis C, Negre-Salvayre A, et al. Small, dense HDL3 particles attenuate apoptosis in endothelial cells: pivotal role of apolipoprotein A-I. J Cell Mol Med 2010; 14: 608-20.

109. Robins SJ, Collins D, Wittes JT, et al. Relation of gemfibrozil treatment and lipid levels with major coronary events: VAHIT: a randomized controlled trial. JAMA 2001; 285: 158591.

110.Navab M, Anantharamaiah GM, Reddy ST, et al. Oral D-4F causes formation of prebeta high-density lipoprotein and improves high-density lipoprotein-mediated cholesterol efflux and reverse cholesterol transport from macrophages in apolipoprotein E-null mice. Circulation 2004; 109: 321520.

111.Van Lenten BJ, Navab M, Shih D, et al. The role of highdensity lipoproteins in oxidation and inflammation. Trends Cardiovasc Med 2001; 11: 155-61.

112. Kontush A, Chapman MJ. Antiatherogenic function of HDL particle subpopulations: focus on antioxidative activities. Curr Opin Lipidol 2010; 21: $312-8$.

113.Skajaa T, Cormode DP, Falk E, Mulder WJM, Fisher EA, Fayad ZA. High -density lipoprotein- based contrast agents fpr multimodal imaging of atherosclerosis. Arterioscler Thromb Vasc Biol 2010; 30: 169-76.

114.Shaul PW, Smart EJ, Robinson LJ, et al. Acylation targets emdothelial nitric-oxide synthase to plasmalemmal caveolae. J Biol Chem. 1996; 271: 6518-22.

115.Garcia-Cardena G, Oh P, Liu J, Schnitzer JE, Sessa WC. Targeting of nitric oxide synthase to endothelial cell caveolae via palmitoylation: implications for nitric oxide signaling. Proc Natl Acad Sci USA 1996; 93: 6448-53.

116.Chang WJ, Rothberg KG, Kamen BA, Anderson RG. Lowering the cholesterol content of MA104 cells inhibits receptormediated transport of folate. J Cell Biol. 1992; 118: 63-9.

117. Blair A, Shaul PW, Yuhanna IS, Conrad PA, Smart EJ. Oxidized low density lipoprotein displaces endothelial nitric-oxide synthase (eNOS) from plasmalemmal caveolae and impairs eNOS activation. J Biol Chem. 1999; 274: 32512-9.

118.Uittenbogaard A, Shaul PW, Yuhanna IS, Blair A, Smart EJ. High density lipoprotein prevents oxidized low density lipoproteininduced inhibition of endothelial nitric-oxide synthase localization and activation in caveolae. J Biol Chem. 2000; 275: 11278-83.

119.KincerJF, UittenbogaardA, DressmanJ, etal. Hypercholesterolemia promotes a CD36-dependent and endothelial nitric-oxide synthase-mediated vascular dysfunction. J Biol Chem. 2002; 277: 23525-33.

120. Yeh $\mathrm{M}$, Cole $\mathrm{AL}$, Choi J, et al. Role for sterol regulatory element-binding protein in activation of endothelial cells by phospholipid oxidation products. Circ Res. 2004; 95: 780-8.

121. Gharavi NM, Baker NA, Mouillesseaux KP, et al. Role of endothelial nitric oxide synthase in the regulation of SREBP activation by oxidized phsopholipids. Circ Res. 2006; 98 : 768-76.

122. Mineo C, Deguchi H, Griffin JH, Shaul PW. Endothelial and antithrombotic actions of HDL. Circ Res 2006; 98: 1352 64.

123. Li D, Yang B, Mehta JL. Ox-LDL induces apoptosis in human coronary artery endothelial cells: role of PKC, PTK, bcl-2, and Fas. Am J Physiol. 1998; 275: H568-76.

124. Choy JC, Granville DJ, Hunt DW, McManus BM. Endothelial cell apoptosis: biochemical characteristics and potential implications for atherosclerosis. J Mol Cell Cardiol. 2001; 


\section{3: $1673-90$.}

125. Dimmeler S, Breitschopf K, Haendeler J, Zeiher AM. Dephosphorylation targets $\mathrm{Bcl}-2$ for ubiquitin-dependent degradation: a link between the apoptosome and the proteasome pathway. J Exp Med. 1999; 189: 1815-22.

126. Welch GN, Loscalzo J. Homocysteine and atherothrombosis. N Engl J Med. 1998; 338: 1042-50.

127. Strawn WB, Ferrario CM. Mechanisms linking angiotensin II and atherogenesis. Curr Opin Lipidol. 2002; 13: 505-12.

128. Li XA, Guo L, Dressman JL, Asmis R, Smart EJ. A novel ligandindependent apoptotic pathway induced by scavenger receptor class B, type I and suppressed by endothelial nitricoxide synthase and high density lipoprotein. J Biol Chem. 2005; 280: 19087-96.

129. Cunningham KS, Gotlieb Al. The role of shear stress in the pathogenesis of atherosclerosis. Lab Invest. 2005; 85 : 9 -23 .

130. Ross R. The pathogenesis of atherosclerosis: a perspective for the 1990s. Nature. 1993; 362: 801-9.

131. Gotlieb Al, Silver MD. Atherosclerosis: pathology and pathogenesis. In: Gotlieb AI, Schoen FJ, Silver MD, eds. Cardiovascular Pathology. 3rd ed. New York: Churchill Livingstone; 2001.

132. Niimi Y, Azuma H, Hirakawa K. Repeated endothelial removal augments intimal thickening and attenuates EDRF release. Am J Physiol. 1994; 266: H1348-56.

133. Rossig L, Dimmeler S, Zeiher AM. Apoptosis in the vascular wall and atherosclerosis. Basic Res Cardiol. 2001; 96: 11-22.

134. Werner N, Junk S, Laufs $\mathrm{U}$, et al. Intravenous transfusion of endothelial progenitor cells reduces neointima formation after vascular injury. Circ Res. 2003; 93: e17-e24.

135. Shah PK, Kaul S, Nilsson J, Cercek B. Exploiting the vascular protective effects of high-density lipoprotein and its apolipoproteins: an idea whose time for testing is coming. Part II. Circulation. 2001; 104: 2498-502.

136. Assmann G, Nofer JR. Atheroprotective effects of high-density lipoproteins. Annu Rev Med. 2003; 54: 321-41.

137. Durand E, Scoazec A, Lafont $\mathrm{A}$, et al. In vivo induction of endothelial apoptosis leads to vessel thrombosis and endothelial denudation: a clue to the understanding of the mechanisms of thrombotic plaque erosion. Circulation. 2004 ; 109: 2503-6.

138. Barter PJ, Nicholls S, Rye KA, Anantharamaiah GM, Navab M, Fogelman AM. Antiinflammatory properties of HDL. Circ Res. 2004; 95: 764-72.

139. Vane JR, Botting RM. Pharmacodynamic profile of prostacyclin. Am J Cardiol. 1995; 75:3 A-10A.

140. Fleisher LN, TallAR, Witte LD, Miller RW, Cannon PJ. Stimulation of arterial endothelial cell prostacyclin synthesis by high density lipoproteins. J Biol Chem. 1982; 257: 6653-5.

141. Spector AA, Scanu AM, Kaduce TL, Figard PH, Fless GM, Czervionke RL. Effect of human plasma lipoproteins on prostacyclin production by cultured endothelial cells. J Lipid Res. 1985; 26: 288-97.

142. Pomerantz KB, Fleisher LN, Tall AR, Cannon PJ. Enrichment of endothelial cell arachidonate by lipid transfer from high density lipoproteins: relationship to prostaglandin 12 synthesis. J Lipid Res. 1985; 26: 1269-76.

143. Myers DE, Huang WN, Larkins RG. Lipoprotein-induced prostacyclin production in endothelial cells and effects of lipoprotein modification. Am J Physiol. 1996; 271: C150411.

144. Cockerill GW, Saklatvala J, Ridley SH, et al. High-density lipoproteins differentially modulate cytokine-induced expression of E-selectin and cyclooxygenase-2. Arterioscler Thromb Vasc Biol. 1999; 19: 910-17.

145. Norata GD, Callegari E, Inoue H, Catapano AL. HDL3 induces cyclooxygenase- 2 expression and prostacyclin release in human endothelial cells via a p38 MAPK/CRE-dependent pathway: effects on COX-2/PGIsynthase coupling. Arterioscler Thromb Vasc Biol. 2004; 24: 871-7.

146. Vinals M, Martinez-Gonzalez J, Badimon JJ, Badimon L. HDLinduced prostacyclin release in smooth muscle cells is dependent on cyclooxygenase-2 (Cox-2). Arterioscler Thromb Vasc Biol. 1997; 17: 3481-8.

147. Escudero I, Martinez-Gonzalez J, Alonso R, Mata P, Badimon L. Experimental and interventional dietary study in humans on the role of HDL fatty acid composition in PGI2 release and Cox-2 expression by VSMC. Eur J Clin Invest. 2003; 33: 779-86.

148. Martinez-Gonzalez J, Escudero I, Badimon L. Simvastatin potenciates $\mathrm{PGI}(2)$ release induced by $\mathrm{HDL}$ in human VSMC: effect on Cox-2 up-regulation and MAPK signalling pathways activated by HDL. Atherosclerosis. 2004; 174: 305-13.

149. O'Connell BJ, Genest J Jr. High-density lipoproteins and endothelial function. Circulation. 2001; 104: 1978-83.

150. Eren M, Painter CA, Atkinson JB, Declerck PJ, Vaughan DE. Age-dependent spontaneous coronary arterial thrombosis in transgenic mice that express a stable form of human plasminogen activator inhibitor-1. Circulation. 2002; 106: 491-6.

151. Ridker PM, Brown NJ, Vaughan DE, Harrison DG, Mehta JL. Established and emerging plasma biomarkers in the prediction of first atherothrombotic events. Circulation. 2004; 109(suppl IV): IV-6 -IV-19.

152. Norata GD, Banfi C. Pirillo A, et al. Oxidised-HDL3 induces the expression of PAI-1 in human endothelial cells. Role of p38MAPK activation and mRNA stabilization. $\mathrm{Br} J$ Haematol. 2004; 127: 97-104.

153. Naqvi TZ, Shah PK, Ivey PA, Met alolloy MD, Thomas AM, Panicker S, Ahmed A, Cercek B, Kaul S. Evidence that high-density lipoprotein cholesterol is an independent predictor of acute platelet-dependent thrombus formation. Am J Cardiol. 1999; 84: 1011-7.

154. Lerch PG, Spycher MO, Doran JE. Reconstituted high density lipoprotein (rHDL) modulates platelet activity in vitro and $e x$ vivo. Thromb Haemost. 1998; 80: 316-20.

155. Nissen SE, et al. Effect of recombinant ApoA-I Milano on coronary atherosclerosis in patients with acute coronary syndromes: a randomized controlled trial. JAMA. 2003; 290: 2292-300.

156. FDA. Pfizer stops all torcetrapib clinical trials in interest of patient safety [press release]. 2006. http://www.fda.gov/bbs/topics/ NEWS/2006/NEW01514.html.

157. Cuchel M, Rader DJ. Genetics of increased HDL cholesterol levels: insights into the relationship between HDL metabolism and atherosclerosis. Arterioscler Thromb Vasc Biol. 2003; 23: 1710-2.

158. Trigatti BL. Hepatic high-density lipoprotein receptors: roles in lipoprotein metabolism and potential for therapeutic modulation. Curr Atheroscler Rep. 2005; 7: 344-50.

159. Vaisar T, Pennatur $\mathrm{S}$, Green $\mathrm{P}$, et al. Shotgun proteomics implicates protease inhibition and complement activation in the antiinflammatory properties of HDL. J Clin Invest 2007; 117: 746-56. doi:10.1172/JCl26206.

160. Rezaee F, Casetta B, Levels JH, Speijer D, Meijers JC. Proteomic analysis of high-density lipoprotein. Proteomics. $2006 ; 6: 721-30$

161. Heller M, et al. Mass spectrometry-based analytical tools for the molecular protein characterization of human plasma lipoproteins. Proteomics. 2005; 5: 2619-30.

162. Karlsson $H$, Leanderson $P$, Tagesson $C$, Lindahl $M$. Lipoproteomics II: mapping of proteins in high-density lipoprotein using two-dimensional gel electrophoresis and mass spectrometry. Proteomics. 2005; 5: 1431-45.

163. Heinecke JW. The HDL proteome: a marker - and perhaps 
mediator - of coronary artery disease. J Lipid Res 2009: S167-S171.

164. Shiflett AM, Bishop JR, Pahwa A, Hajduk SL. Human high density lipoproteins are platforms for assembly of multicomponent innate immune complexes. J Biol Chem. 2005; 280: 32578-85.

165. Libby P. The molecular mechanisms of the thrombotic complications of atherosclerosis. J Intern Med. 2008; 263: 517-27.

166. Liu H, Sadygov RG, Yates JR 3rd. A model for random sampling and estimation of relative protein abundance in shotgun proteomics. Anal Chem. 2004; 76: 4193-4201.

167. Fu X, Gharib SA, Green PS, et al. Spectral index for assessment of differential protein expression in shotgun proteomics. J Proteome Res. 2008; 7: 845-54.

168. Vergnes L, Baroukh N, Ostos MA, et al. Expression of human apolipoprotein A-I/C-III/A-IV gene cluster in mice induces hyperlipidemia but reduces atherogenesis. Arterioscler Thromb Vasc Biol. 2000; 20: 2267-74.

169. Strunk RC, Kunke KS, Giclas PC. Human peripheral blood monocyte-derived macrophages produce haemolytically active C3 in vitro. Immunology. 1983; 49: 169-174.

170. Rader DJ, Puré E. Lipoproteins, macrophage function, and atherosclerosis: beyond the foam cell? Cell Metab. 2005; 1: 223-30.

171. Davidsson P, Hulthe J, Fagerberg B, Camejo G. Proteomics of apolipoprotein and associated proteins from plasma high density lipoprotein. Arterioscler Thromb Vasc Biol 2010; 30: $156-63$.

172. Perley MJ, Kipnis DM. Plasma insulin responses to oral and intravenous glucose: studies in normal and diabetic subjects. J Clin Invest 1967; 46: 1954-62.

173. Kahn SE, Zraika S, Utzschneider KM, Hull RL. The beta cell lesion in type 2 diabetes: there has to be a primary functional abnormality. Diabetologia 2009; 52:1003-12.

174. Adiels M, Olofsson SO, Taskinen MR, Bore'n J. Diabetic dyslipidaemia. Curr Opin Lipidol 2006; 17:238-46.

175. von Eckardstein A, Schulte H, Assmann G. Risk for diabetes mellitus in middle-aged Caucasian male participants of the PROCAM study: implications for the definition of impaired fasting glucose by the American Diabetes Association. Prospective Cardiovascular Münster. J Clin Endocrinol Metab 2000; 85:3101-8.

176. Kendall DM. The dyslipidemia of diabetes mellitus: giving triglycerides and high-density lipoprotein cholesterol a higher priority? Endocrinol Metab Clin North Am 2005; 34:27-48.

177. TenenbaumA, Motro M, Fisman EZ, et al. Peroxisome proliferatoractivated receptor ligand bezafibrate for prevention of type 2 diabetes mellitus in patients with coronary artery disease. Circulation 2004; 109:2197-2202.

178. Kontush A, Chapman MJ. Why is HDL functionally deficient in type 2 diabetes? Curr Diab Rep 2008; 8:51-59.

179. Brites FD, Cavallero E, de Geitere C, et al. Abnormal capacity to induce cholesterol efflux and a new LpA-I prebeta particle in type 2 diabetic patients. Clin Chim Acta 1999; 279:1-14.

180. Syvänne M, Castro G, Dengremont C, et al. Cholesterol efflux from Fu5AH hepatoma cells induced by plasma of subjects with or without coronary artery disease and noninsulindependent diabetes: importance of LpA-I:A-II particles and phospholipid transfer protein. Atherosclerosis 1996; 127:245-53.

181. Nobécourt E, Jacqueminet $\mathrm{S}$, Hansel B, et al. Defective antioxidative activity of small dense HDL3 particles in type 2 diabetes: relationship to elevated oxidative stress and hyperglycaemia. Diabetologia 2005; 48:529-38.

182. de Souza JA, Vindis C, Hansel B, et al. Metabolic syndrome features small, apolipoprotein A-I-poor, triglyceride- rich HDL3 particles with defective antiapoptotic activity. Atherosclerosis 2008; 197:84-94.

183. Getz GS, Reardom CA. High-density lipoprotein function in regulating insulin secretion: possible relevance to metabolic syndrome. Arterioscler Thromb Vasc Biol 2010; 30: $1497-9$.

184. Brown MS, Goldstein JL. The SREBP pathway: regulation of cholesterol metabolism by proteolysis of a membranebound transcription factor. Cell 1997; 89: 331-40.

185. Le Lay S, Krief S, Farnier C, et al. Cholesterol, a cell sizedependent signal that regulates glucose metabolism and gene expression in adipocytes. J Biol Chem 2001; 276: 16904-10.

186. Hao M, Head WS, Gunawardana SC, Hasty AH, Piston DW. Direct effect of cholesterol on insulin secretion. A novel mechanism for pancreatic $\beta$-cell dysfunction. Diabetes 2007; 56: 2328-38.

187. Drew BG, Duffy SJ, Formosa MF, et al. High-density lipoprotein modulates glucose metabolism in patients with type 2 diabetes mellitus. Circulation. 2009; 119: 2103-11.

188. Brunham LR, Kruit JK, Pape TD, et al. Beta-cell ABCA1 influences insulin secretion, glucose homeostasis and response to thiazolidinedione treatment. Nat Med. 2007; 13: $340-7$

189. Roehrich ME, Mooser V, Lenain V, et al. Insulin-secreting betacell dysfunction induced by human lipoproteins. J Biol Chem. 2003; 278: 18368-75.

190. Abderrahmani A, Niederhauser G, Favre D, et al. Human highdensity lipoprotein particles prevent activation of the JNK pathway induced by human oxidised low-density lipoprotein particles in pancreatic beta cells. Diabetologia. 2007; 50: $1304-14$.

191. Rutti S, Ehses JA, Sibler RA, et al. Low- and high-density lipoproteins modulate function, apoptosis, and proliferation of primary human and murine pancreatic beta-cells. Endocrinology. 2009; 150: 4521-30

192. Fryirs MA, Barter PJ, Appavoo M, et al. Effects of high density lipoproteins on pancreatic $\beta$-cell insulin secretion. Arterioscler Thromb Vasc Biol 2010; 30: 1642-8.

193. Vergeer M, Brunham LR, Koetsveld J, et al. Carriers of loss - of - function mutations in ABCA1 display pancreatic $\beta$ - cell dysfunction. Dian Care 2010; 33: 869-74.

194. Shao B, Pennathur S, Pagani I, et al. Dysfunctional HDL: modifying apolipoprotein A-I. by malondialdehyde, but not by an array of other reactive carbonyls, blocks cholesterol efflux by the abca1 pathway. J Biol Chem. 2010; 285: 18473-84

195. Passarelli M, Tang C, McDonald TO, et al. Advanced glycation end product precursors impair ABCA1-dependent cholesterol removal from cells. Diabetes. 2005; 54: 2198 -205 .

196. Kruit JK, Brunham LR, Verchere CN, Hayden MR. HDL and LDL cholesterol significantly influence $\beta$-cell function in type 2 diabetes mellitus. Curr Opin Lipidol 2010; 21: 178-85.

197. Walter M. Interrelationships among HDL metabolism, aging, and atherosclerosis. Arterioscler Thromb Vasc Biol 2009; 29: 1244-50.

198. Ben-Porath I, Weinberg RA. When cells get stressed: an integrative view of cellular senescence. J Clin Invest. 2004; 113: 8-13.

199. Chang E, Harley CB. Telomere length and replicative aging in human vascular tissues. Proc Natl Acad Sci USA. 1995; 92: $11190-4$

200. Kuro-o M. Klotho as a regulator of oxidative stress and senescence. Biol Chem. 2008; 389: 233-41.

201. Arking DE, Becker DM, Yanek LR, et al., KLOTHO allele status and the risk of early-onset occult coronary artery disease. Am J Hum Genet. 2003; 72: 1154-61. 
202. Arking DE, Atzmon G, Arking A, Barzilai N, Dietz HC. Association between a functional variant of the KLOTHO gene and highdensity lipoprotein cholesterol, blood pressure, stroke, and longevity. Circ Res. 2005; 96: 412-8.

203. Nofer JR, Kehrel B, Fobker M, Levkau B, Assmann G, von Eckardstein A. HDL and arteriosclerosis: beyond reverse cholesterol transport. Atherosclerosis. 2002; 161: 1-16.

204. McCallum CD, Epand R. Insulin receptor autophosphorylation and signaling is altered by modulation of membrane physical properties. Biochemistry. 1995; 34: 1815-24.

205. Unger RH. Klotho-induced insulin resistance: a blessing in disguise? Nat Med. 2006; 12: 56-7.

206. Yvan-Charvet L, Pagler T, Gautier EL. ATP-binding cassette transporters and HDL suppress hematopoietic stem cell proliferation. Science. 2010; 25; 328: 1689-93.

207. Lingwood D, Simons K. Lipid rafts as a membrane-organizing principle. Science 2010; 327: 46-50.

208. Giebel B, Corbeil D, Beckmann J, et al. Segregation of lipid raft markers including CD133 in polarized human hematopoietic stem and progenitor cells. Blood 2004; 104: 2332-8.

209. Vitols S, Björkholm B, Gahrton G, Peterson C. Hypocholestherolaemia in malignancy due to elevated low - density lipoprotein - receptor activity in tumour cells: evidence from studies in patients with leukaemia. Lancet $1985 ; 326: 1150-3$

210. Peeters SD, van der Kolk DM, de Haan G. Selective expression of cholesterol metabolism genes in normal CD34+CD38cells with a heterogeneous expression pattern in AML cells. Exp Hematol 2006; 34: 622-30.

211.Feldman DL, Mogelesky TC, Liptak BF, Gerrity RG. Leukocytosis in rabbits with diet-induced atherosclerosis. Arterioscler Thromb 1991; 11: 985-94

212. Hannson GK, Björkholm M. Tackling two diseases with HDL. Science 2010; 328: 1641-2.

213. Navab M, Anantharamaiah GM, Beddy ST, Van Lenten BJ, Fogelman AM. HDL as a biomarker, potential therapeutic target, and therapy. Diabetes 2009; 58: 2711-7.

214. Briel M, Ferreira-Gonzalez I, You JJ, et al. Association between change in high density lipoprotein cholesterol and cardiovascular disease morbidity and mortality: systematic review and meta-regression analysis. BMJ. 2009; 338: b92.

215. Singh IM, Shishehbor MH, Ansell BJ. High-density lipoprotein as a therapeutic target: a systematic review. JAMA. 2007;298:786-98.

216. Van Lenten BJ, Navab M, Anantharamaiah GM, Buga GM, Reddy ST, Fogelman AM. Multiple indications for anti-inflammatory apolipoprotein mimetic peptides. Curr Opin Investig Drugs. 2008; 9: 1157-62.

217. Navab M, Shechter I, Anantharamaiah GM, Reddy ST, Van Lenten BJ, Fogelman AM. Structure and function of HDL mimetics. Arterioscler Thromb Vasc Biol 2010; 30: 164-8.

218. Mendez AJ. The promise of apolipoprotein A-1 mimetics. Curr Opin Endocrinol Diabetes Obes 2010; 17: 171-6.

219. Navab M, Anantharamaiah GM, Hama S, et al. D-4F and statins synergize to render $\mathrm{HDL}$ antiinflammatory in mice and monkeys and cause lesion regression in old apolipoprotein E-null mice. Arterioscler Thromb Vasc Biol. 2005; 25: 1426 32.

220. Van Lenten BJ, Wagner AC, Navab M, et al. D-4F, an apolipoprotein A-I mimetic peptide, inhibits the inflammatory response induced by influenza $A$ infection of human type II pneumocytes. Circulation. 2004;110:3252-8.
221. Navab M, Anantharamaiah GM, Hama S, et al. Oral administration of an Apo A-I mimetic peptide synthesized from D-amino acids dramatically reduces atherosclerosis in mice independent of plasma cholesterol. Circulation. 2002; 105: $290-2$.

222. Garber DW, Datta G, Chaddha M, et al.. A new synthetic class A amphipathic peptide analogue protects mice from dietinduced atherosclerosis. J Lipid Res. 2001; 42: 545-52.

223. Bloedon LT, Dunbar R, Duffy D, et al. Safety, pharmacokinetics, and pharmacodynamics of oral apoA-I mimetic peptide D-4F in high-risk cardiovascular patients. J Lipid Res. 2008; 49: $1344-52$

224. Navab M, Ruchala P, Waring AJ, et al. A novel method for oral delivery of apolipoprotein mimetic peptides synthesized from all L-amino acids. J Lipid Res. 2009; 50: 1538-47.

225. D'Souza W, Stonik JA, Murphy A, et al. Structure/function relationships of apolipoproein A-1 mimetic peptides. Circ Res 2010; 107: 217-27.

226. Larrede S, Quinn CM, Jessup W, et al. Stimulation of cholesterol efflux by LXR agonists in cholesterol - loaded human macrophages is ABCA1 - dependent but ABCG1 - independent. Arterioscler Thromb Vasc Biol 2009; 29: 1930-6.

227. Joseph SB, McKilligin E, Pei L, et al. Synthetic LXR ligand inhibits the development of atherosclerosis in mice. Proc Natl Acad Sci USA. 2002; 99: 7604-9.

228. Levin N, Bischoff ED, Daige $C L$, et al. Macrophage liver $X$ receptor is required for antiatherogenic activity of LXR agonists. Arterioscler Thromb Vasc Biol. 2005; 25: 135-42.

229. Cignarella A, Engel T, von Eckardstein A, et al. Pharmacological regulation of cholesterol efflux in human monocyte-derived macrophages in the absence of exogenous cholesterol acceptors. Atherosclerosis. 2005; 179: 229-36.

230. Burke MF, Khera AV, Rader DJ. Polyphenols and cholesterol efflux. Is coffee the next red wine? Circ Res 2010; 106: 627-9.

231. Scalbert A, Williamson G Dietary intake and bioavailability of polyphenols. J Nutr. 2000; 8S(suppl): 2073S-85S.

232. Manach C, Williamson G, Morand C, Scalbert A, Re'me'sy C. Bioavailability and bioefficacy of polyphenols in humans. I. Review of 97 bioavailability studies. Am J Clin Nutr. 2005; 1(suppl): $230 \mathrm{~S}-42 \mathrm{~S}$

233. Manach C, Mazur A, Scalbert A. Polyphenols and prevention of cardiovascular diseases. Curr Opin Lipidol. 2005; 16: $77-84$.

234. Sevov M, Elfineh L, Cavelier LB. Resveratrol regulates the expression of LXR-alpha in human macrophages. Biochem Biophys Res Commun. 2006; 348: 1047-54.

235. Berrougui H, Grenier G, Loued S, Drouin G, KhalilA. Anew insight into resveratrol as an atheroprotective compound: inhibition of lipid peroxidation and enhancement of cholesterol efflux. Atherosclerosis. 2009; 207: 420-7.

236. Xia M, Hou M, Zhu $\mathrm{H}$, et al.Anthocyanins induce cholesterol efflux from mouse peritoneal macrophages: the role of the peroxisome proliferatoractivated receptor \{gamma\}-liver $X$ receptor \{alpha\}-ABCA1 pathway. J Biol Chem. 2005; 280: 36792-801.

237. Uto-Kondo $\mathrm{H}$, Ayaori $\mathrm{M}$, Ogura $\mathrm{M}$, et al. Coffee consumption enhances high-density lipoprotein-mediated cholesterol efflux in macrophages. Circ Res. 2010; 106: 779-87.

238. Monteiro M, Farah A, Perrone D, Trugo LC, Donangelo C. Chlorogenic acid compounds from coffee are differentially absorbed and metabolized in humans. J Nutr. 2007; 137: 2196-201. 